\title{
Why are labor markets in Spain and Germany so different?*
}

\author{
Miguel Casares ${ }^{\dagger}$ \\ Universidad Pública de Navarra
}

\author{
Jesús Vázquez \\ Universidad del País Vasco (UPV/EHU)
}

October 4, 2016

\begin{abstract}
The volatility of unemployment fluctuations has been about 3 times higher in Spain than in Germany over the recent business cycles (1996-2013). In contrast, fluctuations of the rate of wage inflation were significantly more volatile in Germany than in Spain. We estimate a New-Keynesian model and find several explanatory factors: wage rigidity has been higher in Spain, the labor force has been more elastic in Germany than in Spain, large and persistent shocks augmenting the labor force have been estimated for Spain whereas in Germany there have been substantial shocks reducing the intensity of hours per worker, and the ECB's policy design brought monetary shocks with much greater influence to the Spanish unemployment.
\end{abstract}

Keywords: unemployment, Germany versus Spain, DSGE models.

JEL codes: E12, E23, E32.

\footnotetext{
*We are grateful for comments from Raf Wouters and participants at the 2015 Bilbao Dynamic Macroeconomics Workshop. Miguel Casares and Jesús Vázquez acknowledge financial support from the Spanish Ministerio de Economía (research projects ECO2015-64330-P and ECO2013-43773P, respectively). The second author also acknowledges financial support from the Basque Government and the University of the Basque Country (research grant codes IT-793-13 and UFI11/46, respectively). ${ }^{\dagger}$ Departamento de Economía, Universidad Pública de Navarra. E-mail: mcasares@unavarra.es (M. Casares).

${ }^{\ddagger}$ Departamento FAE II, Universidad del País Vasco (UPV/EHU). E-mail: jesus.vazquez@ehu.eus (J. Vázquez).
} 


\section{Introduction}

The labor markets of Germany and Spain have shown very different patterns in the latest business cycles. Over the period 1996-2013, the average rate of unemployment has been 15\% in Spain and 8\% in Germany (see Figure 1). The short-run fluctuations of unemployment around these average rates were much more intense in Spain (for the same period the standard deviations of the quarterly series of the unemployment rate are, respectively, $5.5 \%$ in Spain and $1.7 \%$ in Germany). Moreover, there is a lack of business cycle synchronization among the two labor markets: the peak of German unemployment rate was observed around 2006 coinciding with the trough of the Spanish unemployment rate. Meanwhile, the highest rate of unemployment in Spain came at the end of the series, in 2013, when German unemployment reported the lowest rate of the period. ${ }^{1}$ This negative comovement may raise severe difficulties for the centralized monetary policy of the European Central Bank. ${ }^{2}$ Or, put differently, the effects of a single monetary policy over different labor market structures such as Spain and Germany may amplify their differences in their unemployment fluctuations.

Wages also showed differentiated business cycle features for the two countries (see Figure 2). Thus, the standard deviation of the quarterly rate of nominal wage inflation was roughly twice larger in Germany $(0.96 \%)$ than in Spain (0.50\%) from 1996 to 2013. Meanwhile, the rate of average wage inflation, in annualized terms, has been higher in Spain (3.3\%) than in Germany $(2.1 \%)$.

Using the database compiled by Ohanian and Raffo (2012), with the latest update to incorporate data from 2013, we can also look at the adjustments of the intensive margin of labor (hours per worker) across the two countries (see Figure 3). In both countries, there is a downward trend during the sample period 1996-2013. The average number of weekly hours per worker has been lower in Germany, which reflected the higher prevalence of part-time jobs but its short-run variability was higher (the standard deviation of the quarterly rate of growth of the series was $2.8 \%$ in Germany versus $1.9 \%$ in Spain). Remarkably, the German series shows a sharp decline in 2008-09 to account for the use of intensive margin adjustments in response to the reduction of aggregate demand observed during the financial crisis: the internal firm-level flexibility brought a fall in the number of hours per worker to avoid job destruction. Meanwhile, the Spanish series of hours per worker did not show this adjustment leading to further job destruction and a strong increase in the unemployment rate.

Another driving factor for unemployment fluctuations comes from the evolution of the labor supply.

\footnotetext{
${ }^{1}$ Boeri and Jimeno (2016) extensively discuss the divergence of unemployment fluctuations across Euro area countries.

${ }^{2}$ The cross correlation between the quarterly series of the German and Spanish unemployment rates, displayed in Figure 1, is -0.74 .
} 
Looking at the series of the rate of labor force participation (Figure 4), we see a significant upward trend in both Spain and Germany. However, the Spanish labor force grew much more than the German one (from 1996 to 2013 the Spanish participation rate increased from 63\% to $75 \%$ and in Germany from $70 \%$ to $77 \%$ ). The rapid and large rise of the labor force in Spain can be explained by the following three factors:

(i) the arrival of a huge number of immigrants from the rest of the world: foreign population in Spain increased by a factor of 10 during the sample period and most of these immigrants were at their prime working age (Arango, 2013),

(ii) the female incorporation to the labor market: the labor force participation rate for the prime working age of women rose from $58 \%$ to $81 \%$ in Spain whereas in Germany it rose from $75 \%$ to $81 \%$ during the sample period 1996-2013 (Dvorkin and Shell, 2015), and

(iii) the demographic effects of the entry of the baby-boom generation in the labor market: the babyboon generation in Spain was born before the late 1970s whereas the fertility rates in Germany already started to decline around 1967. According to data released in the Spanish Population Census 2011 by the Instituto Nacional de Estadistica, the cohort born between 1967 and 1981, aged 30-44, has 11.8 million people. The next cohort, aged 15-29, has 7.8 million people, whereas the previous cohort, aged 45-59, has 9.5 million people.

In sum, these three demographic shifts were also present in the German labor market but at a lower extent. As shown later in the paper, the pressure of a continuously higher growing labor supply on the Spanish labor market plays a major role in explaining why the Spanish rate of unemployment has been consistently higher than the German one.

The dramatic differences observed in the labor market performance of Spain and Germany seem to be dissociated in their goods markets. As Figure 5 shows from 1996 to 2013, the average rate of growth of real GDP per capita was, in annualized terms, $1.5 \%$ in Germany and $1.2 \%$ in Spain. The volatility of quarterly rate of real GDP growth per capita has been somewhat higher in Germany (the standard deviation of the series was $0.6 \%$ for Spain and $0.9 \%$ for Germany). The comovement of quarterly growth in Spain and Germany has been moderately high (cross correlation of the series of Figure 5 at 0.52 ) which shows a moderate degree of cyclical synchronization among their respective aggregate demands that has not been observed in the labor markets. These sharply differences in the synchronicity features further motivates our focus on the differences between the German and the Spanish labor markets.

What are the underlying forces driving the radical different outcomes in the labour markets of Spain and Germany? Are these different outcomes the result of differences in wage flexibility, hours per worker 
adjustments or labor supply shifts that we have observed empirically? There might also be institutional factors coming from the country-specific labor market reforms. Spain passed laws for major labor market reforms in 2010 and 2012, whereas the Hartz reforms for labor market flexibility in Germany were passed between 2003 and 2005. There might have also been country-specific supply or demand shocks to explain the differences in unemployment variability.

Looking for answers to the previous questions, we will conduct a structural analysis of the labor market fluctuations observed in Germany and Spain. Hence, a DSGE-style dynamic macroeconomic model à la Smets and Wouters (2007) will be extended to deliver fluctuations of unemployment and hours per worker in an environment where both real and nominal frictions interact with a rich variety of shocks. More precisely, the labor market structure generalizes that of Casares (2010) and Casares, Moreno and Vázquez (2014) to include a distinction between employment (extensive margin) and hours worked per worker (intensive margin). Hence, the model combines most of the nominal and real rigidities of full-fledged DSGE models - Calvo-type price stickiness, consumption habits, investment adjustment costs, variable capital utilization, etc. -, with additional labor market frictions affecting both margins of total hours worked.

The organization of the rest of the paper is as follows. Section 2 describes the dynamic macroeconomic model, which is estimated and compared for Germany and Spain in Section 3. Using business-cycle model simulations, Section 4 explores the factors explaining labor market differences. The quarter-to-quarter variability of the rate of unemployment is examined and compared both across countries and across sample periods in Section 5. Finally, Section 6 concludes.

\section{A DSGE model for labor market analysis}

Our model combines traditional assumptions of the dynamic stochastic general equilibrium (DSGE) methodology (Smets and Wouters, 2007) with the introduction of unemployment as the excess supply of labor that results from nominal rigidities on wage setting (Casares, 2010). As one theoretical contribution, we split up the total hours of labor in the two margins of variability: the extensive margin (number of workers) and the intensive margin (number of hours per worker). The firms must face some costs of adjusting both the number of hours per worker and their payroll employment. In addition, we allow for the possibility of a contemporaneous interaction between the supply of workers (i.e. labor force participation) and the rate of unemployment. Thus, we conjecture that when the unemployment rate rises (falls), the amount of people willing to work falls (rises). This negative comovement between the 


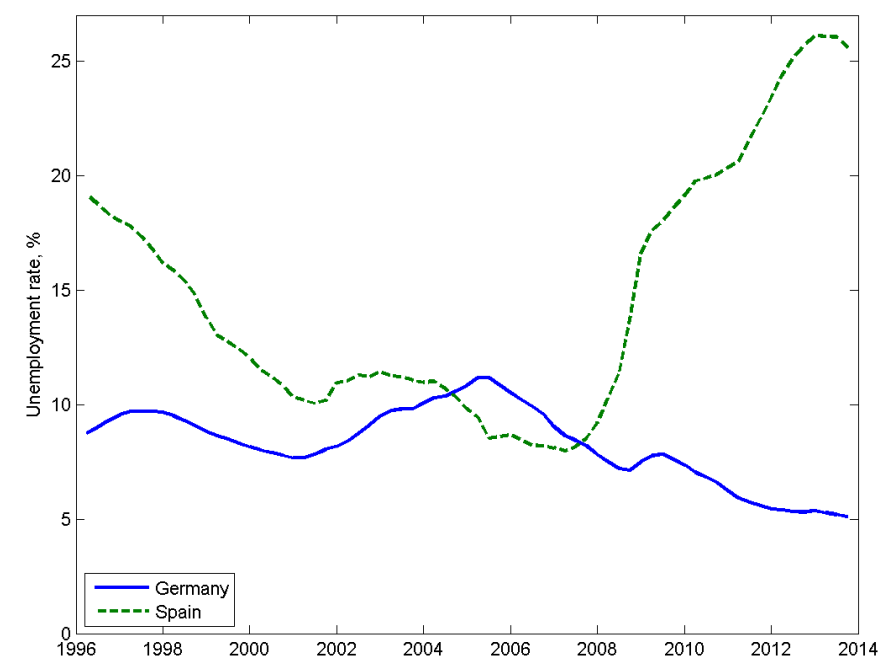

Figure 1: Rate of unemployment in Germany and Spain.

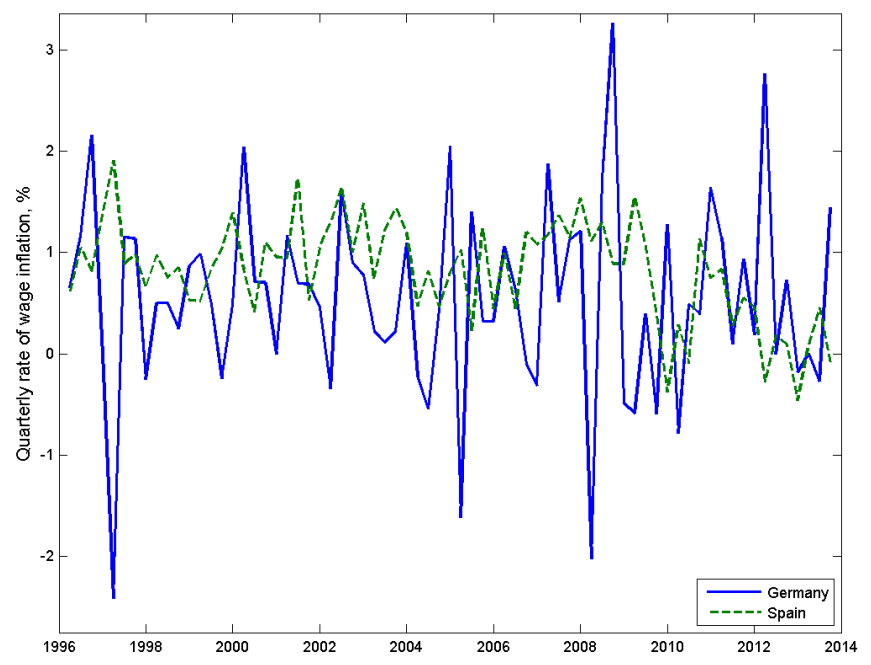

Figure 2: Rate of nominal wage inflation in Germany and Spain. 


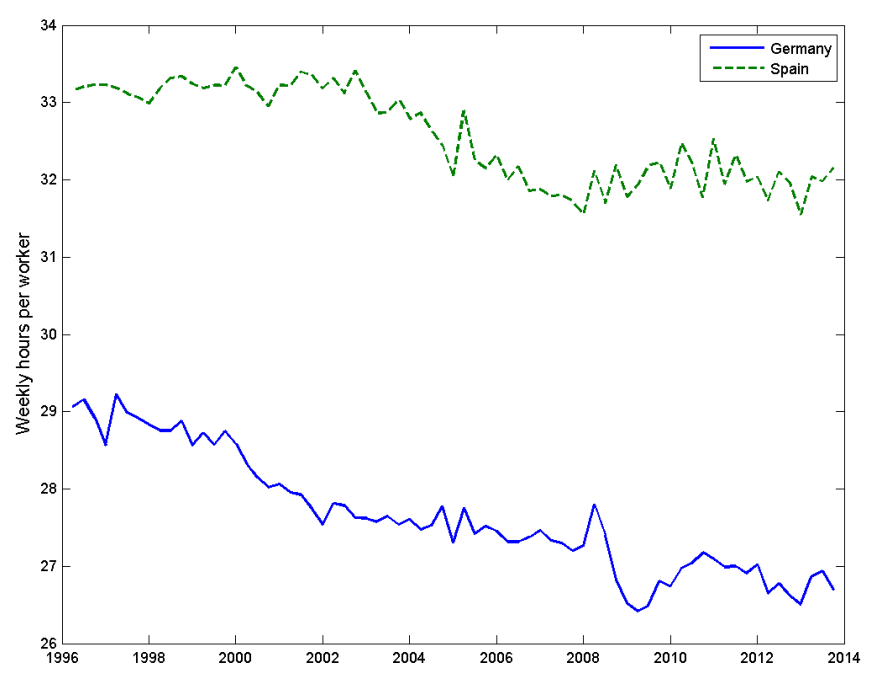

Figure 3: Hours per worker in Germany and Spain.

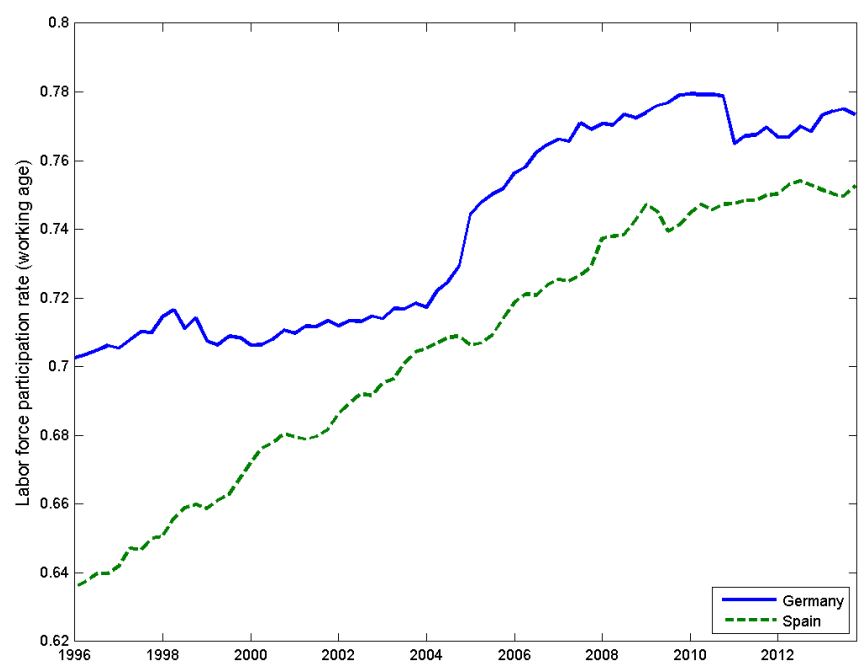

Figure 4: Labor force in Germany and Spain. 


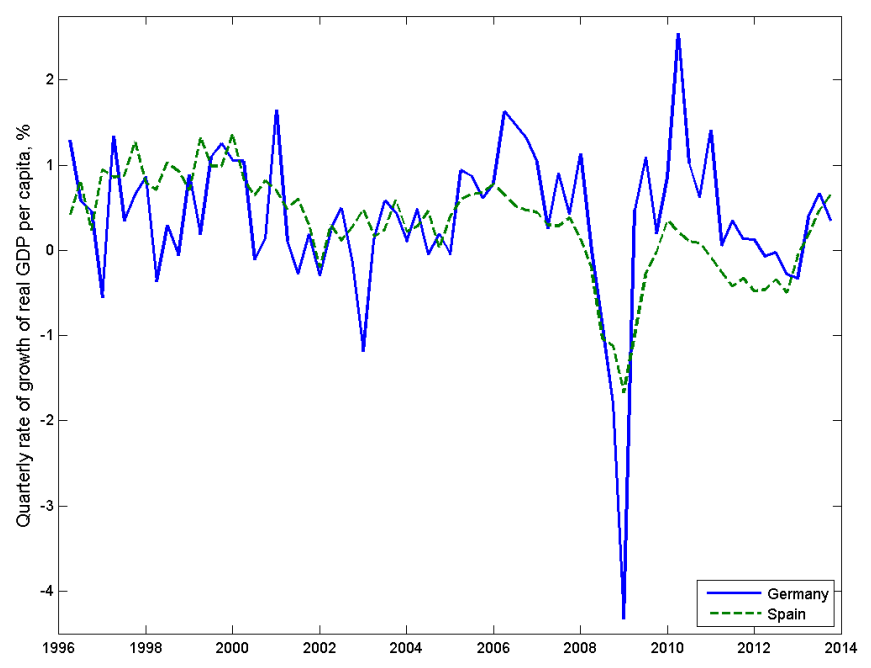

Figure 5: Rate of growth of real GDP per capita in Germany and Spain.

labor force and unemployment can be viewed as a discouragement effect (i.e., when the unemployment rate is high unemployed workers and people thinking about entering the labor market may lost confidence of finding a job and then they may decide to abandon or simply stay out of the labor force). ${ }^{3}$ Moreover, the model setting incorporates two new sources of variability (that were not considered in Smets and Wouters, 2007): a labor force shock for the supply of workers and an adjustment cost shock on the demand for hours per worker at the firm.

\subsection{Households and labor supply}

The representative household supplies labor to all the firms that produce differentiated goods, indexed in the unit interval. Borrowing preferences from Smets and Wouters (2007), and adapting the possibility of unemployment, the period utility function is given by the following non-separable specification:

$$
\left[\frac{1}{1-\sigma_{c}}\left(C_{t}-\lambda C_{t-1}^{A}\right)^{1-\sigma_{c}}\right] \exp \left(\frac{\sigma_{c}-1}{1+\sigma_{l}} \int_{0}^{1}\left(\left(1-u_{t}(i)\right) L_{t}^{s}(i)\right)^{1+\sigma_{l}} d i\right)
$$

where $\sigma_{c}, \sigma_{l}>0$ are the risk aversion and the inverse of Frisch elasticity, respectively; $0<\lambda<1$ is the consumption (external) habit parameter, $C_{t}$ is the current consumption of bundles of goods, $C_{t-1}^{A}$ is lagged aggregate consumption of these bundles, $L_{t}^{s}(i)$ is the supply of total hours at the $i^{\text {th }}$ firm, and $u_{t}(i)$ is the rate of unemployment at the $i^{t h}$ firm. Thus, $\left(1-u_{t}(i)\right) L_{t}^{s}(i)$ is the transformation of the total

\footnotetext{
${ }^{3}$ Conversely, a negative correlation between the labor force and the unemployment rate can also result from an encouragement effect when the unemployment rate is low because people thinking about entering the labor market may gain confidence of finding a job.
} 
hours of firm-level labor supply in units of effective labor (i.e., $u_{t}(i)$ can be viewed as the probability for a worker of being unemployed at the firm $i$ in period $t$ ). Households maximize intertemporal utility subject to budget constraints like this one to be held in period $t$

$$
\int_{0}^{1} \frac{W_{t}(i)\left(1-u_{t}(i)\right) L_{t}^{s}(i)}{P_{t}} d i+\frac{R_{t}^{k} Z_{t} K_{t-1}}{P_{t}}-a\left(Z_{t}\right) K_{t-1}+\frac{D i v_{t}}{P_{t}}=C_{t}+I_{t}+\frac{B_{t}}{\exp \left(\varepsilon_{t}^{b}\right)\left(1+R_{t}\right) P_{t}}-\frac{B_{t-1}}{P_{t-1}\left(1+\pi_{t}\right)}+T_{t}
$$

where $W_{t}(i)$ is the nominal wage earned in the $i^{t h}$ firm, $P_{t}$ is the aggregate price level, $R_{t}^{k}$ is the rental rate of capital, $Z_{t}$ is the rate of capital utilization, $K_{t-1}$ is the stock of capital accumulated by the household in period $t-1$ and rented to the firms in period $t, a\left(Z_{t}\right)$ is the cost of adjusting capital utilization as an increasing convex function on the utilization rate, Div $v_{t}$ is the aggregate nominal firm dividends, $I_{t}$ is the amount of investment spending on capital accumulation, $B_{t} /\left(1+R_{t}\right)$ is the amount of nominal bonds purchased in period $t$ that yield a nominal interest rate $R_{t}$ conditional to the risk-premium shock $\varepsilon_{t}^{b}$, and $T_{t}$ denotes government lump-sum taxes in real terms.

The first order conditions for consumption and the supply of hours of type $i$ that result from the household optimizing program are

$$
\begin{array}{r}
\left(C_{t}-\lambda C_{t-1}^{A}\right)^{-\sigma_{c}} \exp \left(\frac{\sigma_{c}-1}{1+\sigma_{l}} \int_{0}^{1}\left(\left(1-u_{t}(i)\right) L_{t}^{s}(i)\right)^{1+\sigma_{l}} d i\right)-\Xi_{t}=0, \\
\left(1-u_{t}(i)\right)\left(L_{t}^{s}(i)\right)^{\sigma_{l}}\left(C_{t}-\lambda C_{t-1}^{A}\right)^{1-\sigma_{c}} \exp \left(\frac{\sigma_{c}-1}{1+\sigma_{l}} \int_{0}^{1}\left(\left(1-u_{t}(i)\right) L_{t}^{s}(i)\right)^{1+\sigma_{l}} d i\right) \\
+\Xi_{t} \frac{W_{t}(i)\left(1-u_{t}(i)\right)}{P_{t}}=0,
\end{array}
$$

where $\Xi_{t}$ is the Lagrange multiplier of the budget constraint in period $t$. Inserting (1) in (2) and rearranging terms leads to this supply of labor to the firm $i$

$$
L_{t}^{s}(i)=\left(\frac{W_{t}(i) / P_{t}}{C_{t}-\lambda C_{t-1}^{A}}\right)^{1 / \sigma_{l}} .
$$

Using a log-linear approximation around the balanced-growth path of the model, and taking lower-case letters to represent the log-deviations of the variables, denoted by their upper-case letters, with respect to their balanced-growth (steady-state) values, we obtain

$$
l_{t}^{s}(i)=\frac{1}{\sigma_{l}}\left(w_{t}(i)-p_{t}-\frac{1}{(1-\lambda / \gamma)}\left(c_{t}-(\lambda / \gamma) c_{t-1}\right)\right),
$$

where $\gamma$ is the balanced-growth rate and symmetric equilibrium across households holds for consumption, $c_{t}=c_{t}(i)$. Aggregating labor supply across all types yields

$$
l_{t}^{s}=\frac{1}{\sigma_{l}}\left(w_{t}-p_{t}-\frac{1}{(1-\lambda / \gamma)}\left(c_{t}-(\lambda / \gamma) c_{t-1}\right)\right),
$$


and by subtracting (4) from (3), we reach the relative labor supply equation depending positively on the relative nominal wage

$$
l_{t}^{s}(i)-l_{t}^{s}=\frac{1}{\sigma_{l}}\left(w_{t}(i)-w_{t}\right) .
$$

For the distinction between the extensive and intensive margins, let us decompose the total labor supply of type $i$ as $L_{t}^{s}(i)=N_{t}^{s}(i) H_{t}^{s}(i)$, where $N_{t}^{s}(i)$ is the number of household members willing to work (labor force) at the firm that produces good $i$, and $H_{t}^{s}(i)$ is the amount of hours per worker supplied to firm $i$. The labor force is assumed to be driven by the following equation

$$
N_{t}^{s}(i)=N^{s} \exp \left(\varepsilon_{t}^{N^{s}}-\rho_{n u}\left(u_{t}-u\right)\right), \quad \text { for all } i,
$$

which combines an exogenous $\operatorname{AR}(1)$ component, $\varepsilon_{t}^{N^{s}}$, and a negative response of the labor force to the current deviation of the aggregate rate of unemployment with respect to its steady-state rate, measured by the coefficient $\rho_{n u}>0$. This (encouragement/discouragement) effect captures the interactions between the labor force and the observed current unemployment. Due to perfect symmetry assumed across households, the aggregate labor force is (in loglinear terms)

$$
n_{t}^{s}=\varepsilon_{t}^{N^{s}}-\rho_{n u}\left(u_{t}-u\right)
$$

Hence, introducing the log-linear decomposition of the aggregate labor supply, $l_{t}^{s}=n_{t}^{s}+h_{t}^{s}$, in (4), and also using (6), we can solve for log fluctuations of aggregate hours per worker to obtain

$$
h_{t}^{s}=\frac{1}{\sigma_{l}}\left(w_{t}-p_{t}-\frac{1}{(1-\lambda / \gamma)}\left(c_{t}-(\lambda / \gamma) c_{t-1}\right)\right)-\left(\varepsilon_{t}^{N^{s}}-\rho_{n u}\left(u_{t}-u\right)\right) .
$$

Finally, there are some implications of our labor market structure on the consumption function of the households. Loglinearizing (1) and aggregating across all types of labor yields

$$
\log \Xi_{t}=-\sigma_{c}\left(\frac{1}{1-\lambda / \gamma} c_{t}-\frac{\lambda / \gamma}{1-\lambda / \gamma} c_{t-1}\right)+\frac{\left(\sigma_{c}-1\right)(1-u)^{1+\sigma_{l}} L w}{(1-\lambda / \gamma) c}\left(l_{t}^{s}-\left(u_{t}-u\right)\right),
$$

where the elements with no time subscript denote the values obtained in the detrended steady-state solution. In addition, the loglinearized approximation of the standard first-order condition of bonds is

$$
\log \Xi_{t}-\left(r_{t}-r+\varepsilon_{t}^{b}\right)=E_{t} \log \Xi_{t+1}
$$

which introduces the real interest rate as the difference between the nominal interest rate and expected inflation, $r_{t}=R_{t}-E_{t} \pi_{t+1}$. Using (8) and the corresponding expression for period $t+1$ in (9) brings a consumption function featuring consumption habits, a risk-premium shock and a response to effective labor fluctuations

$c_{t}=\frac{\lambda / \gamma}{1+\lambda / \gamma} c_{t-1}+\frac{1}{1+\lambda / \gamma} E_{t} c_{t+1}-\frac{1-\lambda / \gamma}{\sigma_{c}(1+\lambda / \gamma)}\left(r_{t}-r+\varepsilon_{t}^{b}\right)+\frac{\left(\sigma_{c}-1\right)\left(1-u^{n}\right)^{1+\sigma_{l}} N H w / c}{\sigma_{c}(1+\lambda / \gamma)}\left(l_{t}^{s}-E_{t} l_{t+1}^{s}-\left(u_{t}-E_{t} u_{t+1}\right)\right)$ 


\section{$2.2 \quad$ Firms and labor demand}

Labor demand extends the framework of Casares et al. (2014) to distinguish between the two labor margins at the firm level. Thus, total labor demand of type $i$ is $L_{t}^{d}(i)=H_{t}^{d}(i) N_{t}^{d}(i)$ where $N_{t}^{d}(i)$ is the demand for jobs-workers (extensive margin) and $H_{t}^{d}(i)$ is the hourly utilization rate for each worker (intensive margin).

Firms have access to a Cobb-Douglas production technology and sell their output in a monopolistically competitive market à la Dixit and Stiglitz (1977). Labor adjustments are costly both in the intensive and the extensive margins. On the one hand, there is an adjustment cost in total labor, $A C_{t}(i)$, measured by the following function

$$
A C_{t}(i)=\frac{e^{\varepsilon_{t}^{h}} c\left(H_{t}^{d}(i)\right)}{N_{t}^{d}(i)},
$$

where $c\left(H_{t}^{d}(i)\right)$ is increasing on $H_{t}^{d}(i)$ and $\varepsilon_{t}^{h}$ is an exogenous $\mathrm{AR}(1)$ shock. Notice also that $A C_{t}(i)$ incorporates an economies-of-scale effect since the adjustment costs associated with changes in the intensive margin decreases with the size of the extensive margin, $N_{t}^{d}(i)$. On the other hand, there is a fixed cost $\kappa>0$ of keeping workers active for payroll employment $N_{t}^{d}(i)$. In short, these two types of costs result in a trade-off between the two labor margins for the representative firm.

In turn, the representative firm will determine the decomposition of total labor demand, $L_{t}^{d}(i)$, between the intensity of job utilization (number of hours per worker, $\left.H_{t}^{d}(i)\right)$ and the payroll employment (number of active jobs, $\left.N_{t}^{d}(i)\right)$ by maximizing the following profit (earnings) function

$$
e_{t}(i)=\frac{P_{t}(i)}{P_{t}} Y_{t}(i)-\frac{W_{t}(i)}{P_{t}}\left(1+\frac{e^{\varepsilon_{t}^{h}} c\left(H_{t}^{d}(i)\right)}{N_{t}^{d}(i)}\right) L_{t}^{d}(i)-\frac{R_{t}^{k}}{P_{t}} K_{t}^{d}(i)-\kappa N_{t}^{d}(i),
$$

subject to $L_{t}^{d}(i)=H_{t}^{d}(i) N_{t}^{d}(i)$. The first order conditions with respect to $H_{t}^{d}(i)$ and $N_{t}^{d}(i)$ turn out to be, respectively,

$$
\begin{aligned}
\frac{P_{t}(i)}{P_{t}} \frac{\partial Y_{t}(i)}{\partial H_{t}^{d}(i)}-\frac{W_{t}(i)}{P_{t}} N_{t}^{d}(i)-\frac{W_{t}(i)}{P_{t}}\left(e^{\varepsilon_{t}^{h}} c^{\prime}\left(H_{t}^{d}(i)\right) H_{t}^{d}(i)+e^{\varepsilon_{t}^{h}} c\left(H_{t}^{d}(i)\right)\right) & =0 \\
\frac{P_{t}(i)}{P_{t}} \frac{\partial Y_{t}(i)}{\partial N_{t}^{d}(i)}-\frac{W_{t}(i)}{P_{t}} H_{t}^{d}(i)-\kappa & =0 .
\end{aligned}
$$

Noticing $\frac{\partial Y_{t}(i)}{\partial H_{t}^{d}(i)}=\frac{\partial Y_{t}(i)}{\partial N_{t}^{d}(i)} \frac{N_{t}^{d}(i)}{H_{t}^{d}(i)}$ within a Cobb-Douglas technology, we transform (11) as follows

$$
\frac{P_{t}(i)}{P_{t}} \frac{\partial Y_{t}(i)}{\partial N_{t}^{d}(i)} \frac{N_{t}^{d}(i)}{H_{t}^{d}(i)}-\frac{W_{t}(i)}{P_{t}} N_{t}^{d}(i)-\frac{W_{t}(i)}{P_{t}}\left(e^{\varepsilon_{t}^{h}} c^{\prime}\left(H_{t}^{d}(i)\right) H_{t}^{d}(i)+e^{\varepsilon_{t}^{h}} c\left(H_{t}^{d}(i)\right)\right)=0,
$$

and multiplying by $\frac{H_{t}^{d}(i)}{N_{t}^{d}(i)}$, it is obtained

$$
\frac{P_{t}(i)}{P_{t}} \frac{\partial Y_{t}(i)}{\partial N_{t}^{d}(i)}-\frac{W_{t}(i)}{P_{t}} H_{t}^{d}(i)-\frac{W_{t}(i)}{P_{t}} \frac{H_{t}^{d}(i)}{N_{t}^{d}(i)}\left(e^{\varepsilon_{t}^{h}} c^{\prime}\left(H_{t}^{d}(i)\right) H_{t}^{d}(i)+e^{\varepsilon_{t}^{h}} c\left(H_{t}^{d}(i)\right)\right)=0 .
$$


Finally, using (12) in the previous condition yields the following optimal demand for hours

$$
\frac{W_{t}(i)}{P_{t}} \frac{H_{t}^{d}(i)}{N_{t}^{d}(i)}\left(e^{\varepsilon_{t}^{h}} c^{\prime}\left(H_{t}^{d}(i)\right) H_{t}^{d}(i)+e^{\varepsilon_{t}^{h}} c\left(H_{t}^{d}(i)\right)\right)=\kappa .
$$

In equilibrium, the decision of the firm makes the marginal cost of adjusting the intensive margin -lefthand side of (13)- be equal to the marginal cost of adjusting the extensive margin -right-hand side of (13)-. Taking a log-linear approximation in (13) and assuming an adjustment cost function for hours, $c\left(H_{t}^{d}(i)\right)$, with the same properties as the capital utilization cost function of Christiano et al. (2005) results in the following dynamic equation for the fluctuations of the demand for hours per worker ${ }^{4}$

$$
\left(2+\frac{\omega_{H}}{1-\omega_{H}}\right) h_{t}^{d}(i)=n_{t}^{d}(i)-\left(w_{t}(i)-p_{t}\right)-\varepsilon_{t}^{h},
$$

where $\omega_{H}=\frac{c^{\prime \prime}(H)}{c^{\prime}(H)}$ is the steady-state elasticity of the marginal adjustment cost of changing hours per worker with respect to the number of hours per worker. A higher adjustment cost elasticity reduces the variability of hours per worker.

The wage setting procedure is determined by the log fluctuations in the firm-level demand for labor $l_{t}^{d}(i)$. From standard optimizing behavior, the labor demand of firm $i$ equalizes the ratio of marginal products of labor and capital to the relative input prices, including the adjustment costs $A C_{t}(i)$,

$$
\frac{1-\alpha}{\alpha} \frac{K_{t}^{d}(i)}{L_{t}^{d}(i)}=\frac{\left(1+A C_{t}(i)\right) W_{t}(i) / P_{t}}{R_{t}^{k} / P_{t}},
$$

where $0<\alpha<1$ is the capital share in the Cobb-Douglas technology. ${ }^{5}$ The log-linearized version of (15) is $^{6}$

$$
l_{t}^{d}(i)=k_{t}^{d}(i)-\left(w_{t}(i)-p_{t}\right)+r_{t}^{k}
$$

Assuming a Cobb-Douglas technology with fixed costs as in Smets and Wouters (2007), the loglinearized production function is

$$
y_{t}(i)=\Phi_{y}\left((1-\alpha) l_{t}^{d}(i)+\alpha k_{t}^{d}(i)+\varepsilon_{t}^{a}\right)
$$

where $\varepsilon_{t}^{a}$ is an $\operatorname{AR}(1)$ total factor productivity technology shock and $\Phi_{y}$ is the steady-state markup (equivalent to 1 plus the ratio of fixed costs of output in steady state). This technology implies the log fluctuations of firm-specific capital demand

$$
k_{t}^{d}(i)=\frac{1}{\alpha}\left(\Phi_{y}^{-1} y_{t}(i)-(1-\alpha) l_{t}^{d}(i)-\varepsilon_{t}^{a}\right) .
$$

\footnotetext{
${ }^{4}$ The steady-state properties of the hour adjustment cost function are $c(H)=0, \frac{c^{\prime \prime}(H)}{c^{\prime}(H)}=\omega_{H}$ and the level of hours per worker in the steady state is normalized at $H=1$.

${ }^{5}$ It can be noticed that the real marginal cost of firm $i$ in period $t$ is $M C_{t}(i)=\frac{\left(\left(1+a c_{t}(i)\right) W_{t}(i) / P_{t}\right)^{1-\alpha}\left(R_{t}^{k} / P_{t}\right)^{\alpha}}{\exp \left(\varepsilon_{t}^{a}\right) \alpha^{\alpha}(1-\alpha)^{1-\alpha}}$.

${ }^{6}$ Notice that the costs of adjusting the intensive margin do not enter in the log-linearized optimality equation due to their steady-state properties (i.e. $c(H)=0$ ).
} 
Substituting the value of $k_{t}^{d}(i)$ from the last expression in the labor demand equation (16) and rearranging terms results in

$$
l_{t}^{d}(i)=\Phi_{y}^{-1} y_{t}(i)-\alpha\left(\left(w_{t}(i)-p_{t}\right)-r_{t}^{k}\right)-\varepsilon_{t}^{a} .
$$

As is standard in a Dixit-Stiglitz monopolistic competition framework, demand-determined output is inversely related to the relative price

$$
y_{t}(i)=y_{t}-\theta\left(p_{t}(i)-p_{t}\right)
$$

where $\theta>0$ defines the elasticity of demand and the relative price is $p_{t}(i)-p_{t}$. Inserting (18) in (17) gives

$$
l_{t}^{d}(i)=\Phi_{y}^{-1} y_{t}-\theta \Phi_{y}^{-1}\left(p_{t}(i)-p_{t}\right)-\alpha\left(\left(w_{t}(i)-p_{t}\right)-r_{t}^{k}\right)-\varepsilon_{t}^{a},
$$

and taking the difference between firm-specific and aggregate values results in a relative labor demand equation depending on both relative prices and relative wages

$$
l_{t}^{d}(i)-l_{t}^{d}=-\theta \Phi_{y}^{-1}\left(p_{t}(i)-p_{t}\right)-\alpha\left(w_{t}(i)-w_{t}\right),
$$

which introduces $l_{t}^{d}$ as the log-deviation from steady state of demand-determined employment obtained from the aggregation of log deviations on firm-specific labor demand: $l_{t}^{d}=\int_{0}^{1} l_{t}^{d}(i) d i$.

\subsection{Wage setting rigidities and unemployment}

The aggregate rate of unemployment, $u_{t}$, is defined as 1.0 minus the ratio between the aggregate demand for workers and the aggregate labor supply of workers

$$
u_{t}=1-\frac{N_{t}^{d}}{N_{t}^{s}}
$$

In semi-loglinear terms, the aggregate rate of unemployment becomes

$$
u_{t}-u=(1-u)\left(n_{t}^{s}-n_{t}^{d}\right)
$$

where $u^{n}$ is the steady-state rate of unemployment.

Following Casares et al. (2014), nominal wages are either revised to match intertemporal labor supply and demand, or adjusted directly through a standard indexation rule. A constant Calvo (1983) probability determines whether the wage takes the notional equilibrium or sticks to an inertial rule. Let $\xi_{w}$ denote the probability that the wage cannot be revised for labor clearing. The wage setting decision belongs to heterogenous firms, that differ from each other in their history of Calvo signals for both price and wage setting. 
In a log-linear fashion, the nominal wage at the representative $i$ firm is set at the value that results from the intertemporal condition:

$$
E_{t}^{\xi_{w}} \sum_{j=0}^{\infty} \bar{\beta}^{j} \xi_{w}^{j}\left(l_{t+j}^{s}(i)-l_{t+j}^{d}(i)\right)=0
$$

where $l_{t+j}^{s}(i)$ and $l_{t+j}^{d}(i)$ represent the log deviations, in any $t+j$ period, from their respective steady-state levels of the labor supply of workers and the labor demand for jobs of type- $i$ labor, $L_{t+j}^{s}(i)$ and $L_{t+j}^{d}(i)$. In the absence of wage stickiness $\left(\xi_{w}=0\right)$, there would be a perfect matching between fluctuations of firm-level labor supply and labor demand, $l_{t}^{s}(i)=l_{t}^{d}(i)$. We have derived two expressions above that respectively determine the log fluctuations of type- $i$ labor supply, (5), and type- $i$ labor demand, (19), depending upon relative wages and prices. They can be plugged, for any $t+j$ period in condition (21) to reach

$$
E_{t}^{\xi_{w}} \sum_{j=0}^{\infty} \bar{\beta}^{j} \xi_{w}^{j}\left(\frac{1}{\sigma_{l}}\left(w_{t+j}(i)-w_{t+j}\right)+l_{t+j}^{s}+\theta \Phi_{y}^{-1}\left(p_{t+j}(i)-p_{t+j}\right)+\alpha\left(w_{t+j}(i)-w_{t+j}\right)-l_{t+j}^{d}\right)=0 .
$$

The fraction of wages that cannot be set to match intertemporal labor supply and demand are automatically raised by applying an indexation rule that combines a weight $0<\iota_{w}<1$ for lagged inflation, $\pi_{t-1}$, and the complementary weight $1-\iota_{w}$ for the steady-state inflation rate plus a stochastic wage-push shock $\varepsilon_{t}^{w}$, which is generated by an $\operatorname{ARMA}(1,1)$ exogenous process. If firm $i$ cannot revise the labor contract in period $t+j$, it will apply the following nominal wage adjustment ${ }^{7}$

$$
W_{t+j}(i)=W_{t-j-1}(i)\left[\left(1+\pi_{t+j-1}\right)^{\iota_{w}}\left(1+\pi+\varepsilon_{t+j}^{w}\right)^{1-\iota_{w}}\right] .
$$

Using a log-linear approximation to (23), and assuming that the $i$ firm can set the labor-clearing wage in period $t$, we can solve (22) for the relative nominal wage to obtain ${ }^{8}$

$$
w_{t}(i)-w_{t}=-\frac{\left(1-\bar{\beta} \xi_{w}\right)}{\left(\sigma_{l}^{-1}+\alpha\right)(1+\Lambda)} E_{t} \sum_{j=0}^{\infty} \bar{\beta}^{j} \xi_{w}^{j}\left(l_{t+j}^{s}-l_{t+j}^{d}\right)+E_{t} \sum_{j=1}^{\infty} \bar{\beta}^{j} \xi_{w}^{j}\left[\pi_{t+j}^{w}-\iota_{w} \pi_{t+j-1}-\left(1-\iota_{w}\right) \varepsilon_{t+j}^{w}\right],
$$

where $\Lambda$ is a coefficient that results from a non-linear combination of structural parameters. Meanwhile, the wage indexation rule (23) implies a proportional relationship between the relative wage, $w_{t}(i)-w_{t}$, and the rate of wage inflation, $\pi_{t}^{w}$, adjusted by the indexation factors

$$
w_{t}(i)-w_{t}=\frac{\xi_{w}}{1-\xi_{w}}\left[\left(\pi_{t}^{w}-\pi^{w}\right)-\iota_{w}\left(\pi_{t-1}-\pi\right)-\left(1-\iota_{w}\right) \varepsilon_{t}^{w}\right]
$$

\footnotetext{
${ }^{7}$ The wage indexation rule is very similar to the one assumed in Smets and Wouters (2007), with the only difference that we include a cost-push shock $\varepsilon_{t}^{w}$ to replace the wage markup shock of their model.

${ }^{8}$ See Casares et al. (2014) for the derivation. Further details are in a technical appendix available upon request.
} 
Combining (24) and (25) results in the wage inflation equation

$$
\pi_{t}^{w}-\pi^{w}=\bar{\beta} E_{t}\left(\pi_{t+1}^{w}-\pi^{w}\right)+\iota_{w}\left(\pi_{t-1}-\pi\right)-\bar{\beta} \iota_{w}\left(\pi_{t}-\pi\right)-\phi_{w}\left(l_{t}^{s}-l_{t}^{d}\right)+\left(1-\iota_{w}\right)\left(\varepsilon_{t}^{w}-\bar{\beta} E_{t} \varepsilon_{t+1}^{w}\right)
$$

where the slope coefficient $\phi_{w}=\frac{\left(1-\bar{\beta} \xi_{w}\right)\left(1-\xi_{w}\right)}{\xi_{w}\left(\sigma_{l}^{-1}+\alpha\right)(1+\Lambda)}$ is analytically determined by most of the deep parameters of the model.

\subsection{Summary of the new}

From the household optimizing program, the aggregate supply of total hours, in loglinear terms, is

$$
h_{t}^{s}+n_{t}^{s}=\frac{1}{\sigma_{l}}\left[w_{t}-p_{t}-\frac{1}{(1-\lambda / \gamma)}\left(c_{t}-(\lambda / \gamma) c_{t-1}\right)\right],
$$

where the labor force is governed by the following equation

$$
n_{t}^{s}=\varepsilon_{t}^{N^{s}}-\rho_{n u}\left(u_{t}-u\right)
$$

Regarding firm's program, both margins of labor are introduced in the Cobb-Douglas production function to obtain the aggregate and log-linear expression

$$
y_{t}=\Phi_{y}\left[\alpha k_{t}^{s}+(1-\alpha)\left(h_{t}^{d}+n_{t}^{d}\right)+\varepsilon_{t}^{a}\right]
$$

whereas the aggregate demand for hours per worker constrained by the adjustment rigidities is

$$
\left(2+\frac{\omega_{H}}{1-\omega_{H}}\right) h_{t}^{d}=n_{t}^{d}-\left(w_{t}-p_{t}\right)-\varepsilon_{t}^{h},
$$

that incorporates the shock on the adjustment costs of the intensive margin of labor, $\varepsilon_{t}^{h}$, as an additional source of variability from the labor market. The variables that determine the demand for hours per worker are the the level of employment (with a positive effect to allow complementarity), the real wage (with a negative effect) and the exogenous component of the hours adjustment cost function (with a negative effect).

The rate of unemployment only refers to the extensive margin of labor (employment)

$$
u_{t}-u^{n}=\left(1-u^{n}\right)\left(n_{t}^{s}-n_{t}^{d}\right)
$$

and wage inflation depends (inversely) on the gap between total hours supplied and total hours demanded

$$
\begin{aligned}
\pi_{t}^{w}-\pi^{w}=\bar{\beta} E_{t}\left(\pi_{t+1}^{w}-\pi^{w}\right)+\iota_{w}\left(\pi_{t-1}-\pi\right) & -\bar{\beta} \iota_{w}\left(\pi_{t}-\pi\right) \\
& -\phi_{w}\left(\left(h_{t}^{s}+n_{t}^{s}\right)-\left(h_{t}^{d}+n_{t}^{d}\right)\right)+\left(1-\iota_{w}\right)\left(\varepsilon_{t}^{w}-\bar{\beta} E_{t} \varepsilon_{t+1}^{w}\right) .
\end{aligned}
$$


In line with a similar wage-inflation equation derived in Galí (2011), the last equation recalls the original Phillips (1958) empirical curve in the inverse relation linking wage inflation with the rate of unemployment. ${ }^{9}$ Finally, the definition of the aggregate real wage brings the following expression linking the real wage to nominal wage inflation

$$
w_{t}-p_{t}=\left(w_{t-1}-p_{t-1}\right)+\left(\pi_{t}^{w}-\pi^{w}\right)-\left(\pi_{t}-\pi\right) .
$$

This seven-equation system determines solution paths for $h_{t}^{s}, n_{t}^{s}, h_{t}^{d}, n_{t}^{d}, \pi_{t}^{w}-\pi^{w}, w_{t}-p_{t}$ and $u_{t}-u$, given values for demand-determined output, consumption, and the rate of inflation.

As in Smets and Wouters (2007), the overall resource constraint provides demand-determined output fluctuations with the additional variability coming exogenously from an aggregate demand shock cross-correlated to the technology shock. Also borrowing the structural dynamic equations of Smets and Wouters (2007), the combination of the optimal capital utilization rate -subject to adjustment costs- and the stock of capital optimally decided by the household -subject to adjustment costs on changes of investment and an AR(1) investment-specific shock- determines both the fluctuations of capital accumulation and investment spending. The consumption function (10) includes a labor effect, as already discussed above.

The rate of price inflation depends on the fluctuations of the real marginal costs with hybrid backwardlooking and forward-looking dynamics

$$
\pi_{t}-\pi=\frac{\iota_{p}}{1+\bar{\beta} \iota_{p}}\left(\pi_{t-1}-\pi\right)+\frac{\bar{\beta}}{1+\bar{\beta} \iota_{p}} E_{t}\left(\pi_{t+1}-\pi\right)+\frac{\left(1-\bar{\beta} \xi_{p}\right)\left(1-\xi_{p}\right)}{\left(1+\bar{\beta} \iota_{p}\right) \xi_{p} \Phi} m c_{t}+\varepsilon_{t}^{p},
$$

where $\Phi$ depends, among others, on the Calvo probability of wage stickiness to reflect the connections between price setting and wage setting at the (decentralized) firm level, and there is also a price markup $\operatorname{ARMA}(1,1)$ shock, $\varepsilon_{t}^{p}$, that brings exogenous inflation variability. ${ }^{10}$

The model is completed with a monetary policy rule à la Taylor (1993), featuring interest rate smoothing and a response to the change in the output gap as in Smets and Wouters (2007)

$$
R_{t}-R=\rho\left(R_{t-1}-R\right)+(1-\rho)\left[r_{\pi}\left(\pi_{t}-\pi\right)+r_{y} \widetilde{y}_{t}\right]+r_{\Delta y}\left[\widetilde{y}_{t}-\widetilde{y}_{t-1}\right]+\varepsilon_{t}^{R},
$$

where $0<\rho<1, r_{\pi}>1.0, r_{y}, r_{\Delta y}>0, \varepsilon_{t}^{R}$ is an $\operatorname{AR}(1)$ monetary policy shock and the output gap, $\widetilde{y}_{t}$, is defined as the difference between log fluctuations of current output and log fluctuations of natural-rate

\footnotetext{
${ }^{9}$ Galí (2011) incorporates unemployment in a DSGE model by extending the sticky-wage model of Erceg et al. (2000) to have household members with specific labor disutility. Furthermore, the aggregate labor supply is computed at the average real wage that may be different from the aggregate labor demand given by the state of technology and the aggregate demand conditions. By contrast, our model delivers unemployment fluctuations from firm-level mismatches between labor supply and labor demand due to firm-specific wage stickiness.

${ }^{10}$ See Casares et al. (2014) for the details.
} 
potential output, the latter defined as the amount produced if the economy were in a scenario free of nominal rigidities (i.e. Calvo probabilities on both price and wage setting equal to zero, $\xi_{p}=\xi_{w}=0$ ).

The set of dynamic equations and the list of endogenous variables of the model can be reviewed in the technical appendix.

\section{Estimation}

This section is divided in two subsections. The first subsection describes the data used in the estimation and the Bayesian econometric approach used to estimate the DSGE model for each country. The second subsection discusses the different estimation results of labor market parameters found between Germany and Spain.

\subsection{Data and estimation approach}

The model is estimated with quarterly observations of a sample period that begins in the second quarter of 1996 and ends in the fourth quarter of 2013. We take as observable variables nine quarterly time series from both Germany and Spain. German data on the rate of inflation (from the GDP implicit price deflator), the 3-month nominal interest rate, the unemployment rate, and the log differences of the real GDP, real consumption, real investment, and the real wage were downloaded from the Federal Reserve Bank of St. Louis (FRED2) database. ${ }^{11}$ All the Spanish series were also obtained from FRED2, except for the 3-month interest rate and the unemployment rate that were retrieved from BDREMS due to not available data over the whole sample period studied. BDREMS is a database commonly used to estimate DSGE models of the Spanish economy as the REM model of Boscà et al. (2010). Meanwhile, data on the log differences of hours worked per worker (intensive margin) and employment (extensive margin) are coming from the updated database constructed by Ohanian and Raffo (2012). ${ }^{12}$ This database overcomes the lack of data on the intensive margin as it utilizes a consistent measure across OECD countries, which makes it suitable for international labor market comparisons as the one carried out in this paper. Moreover, in line with our representative household DSGE model, variables are measured in per-capita terms when appropriate.

\footnotetext{
${ }^{11}$ The rate of inflation is obtained as the first difference of (the log of) the implicit GDP deflator. The German 3-month rate is an interbank rate (reference code IR3TIB01DEQ156N). The German unemployment rate is "Harmonized unemployment Rate: All Persons for Germany" (reference code DEUURHARMQDSMEI). Finally, the nominal wage is "Hourly Earnings: Private Sector" for the two countries. The German (Spanish) reference code is LCEAPR01DEQ661S (LCEAPR01ESQ661S).

${ }^{12}$ We thank Andrea Raffo for kindly sharing their updated database with us.
} 
The estimation approach follows a standard two-step Bayesian estimation procedure. First, a maximization of the log posterior function is carried out by combining prior information on the parameters with the likelihood of the data. In general, the prior assumptions are identical for the two countries and similar to those assumed in Smets and Wouters (2007) for US data, together with additional prior information associated with the parameters characterizing unemployment. By imposing identical priors for the structural parameters on technology and preferences of the two countries, we might be able to use the information provided by the data to uncover differences between the two labor markets.

In addition, the distinction between the two labor margins brings about a few additional parameters. Thus, the prior distribution of the hours adjustment cost parameter, $\omega_{H}$, follows a beta distribution with mean 0.5 and standard deviation 0.15. Similarly, the prior distributions of the parameters describing persistence and the standard deviation of the innovation associated with each additional shock are identical to the corresponding parameters describing the other $\operatorname{AR}(1)$ shocks of the model. Finally, the prior distribution of the parameter featuring the interaction between the labor force and the unemployment rates, $\rho_{n^{s}, u}$, is a normal distribution with mean 0.5 and a large standard deviation of 2.0 in recognition of our limited information about this interaction.

Preliminary estimation exercises using Spanish data set led to an estimate of the steady-state markup, $\Phi_{y}$, hitting its lower bound value of 1.0. This result implies that Spanish firms would be perfectly competitive, which is inconsistent with the monopolistic competition framework characterizing our DSGE model. As a compromise, we fix $\Phi_{y}=1.2$ (i.e. a steady-state markup of $20 \%$ ) for the two countries. ${ }^{13}$

There is an exception to this general rule of using common priors for the two countries. The prior distribution of the steady-state unemployment rate parameter is assumed to have a higher mean in Spain (15\%) than in Germany (8\%) -but an identical standard deviation of 2.0- in order to incorporate the prior information that the average unemployment rate is roughly twice higher in Spain than in Germany.

\footnotetext{
${ }^{13}$ This value lies inside the confidence band of $(1.17,1.69)$ estimated in Smets and Wouters $(2003$, p. 1143) for the whole Euro area and using a rather different sample period (1980:2-1999:4). Moreover, by setting free $\Phi_{y}$ when estimating the model for Germany, the estimated value is close to 1.5, but the rest of parameter estimates and thus the conclusions of the paper remain robust.
} 
Table 1. Priors and estimated posteriors of selected parameters

\begin{tabular}{|c|c|c|c|c|c|c|c|c|c|}
\hline \multirow[t]{3}{*}{ Sample: 1996-2013 } & \multicolumn{3}{|c|}{ Priors } & \multicolumn{6}{|c|}{ Posteriors } \\
\hline & \multirow[b]{2}{*}{ Distr } & \multirow[b]{2}{*}{ Mean } & \multirow[b]{2}{*}{ Std D. } & \multicolumn{3}{|c|}{ Germany } & \multicolumn{3}{|c|}{ Spain } \\
\hline & & & & Mean & $5 \%$ & $95 \%$ & Mean & $5 \%$ & $95 \%$ \\
\hline$\xi_{p}:$ price Calvo probability & Beta & 0.50 & 0.10 & 0.84 & 0.78 & 0.91 & 0.81 & 0.75 & 0.87 \\
\hline$\xi_{w}$ : wage Calvo probability & Beta & 0.50 & 0.10 & 0.61 & 0.47 & 0.76 & 0.93 & 0.91 & 0.95 \\
\hline$\iota_{p}:$ price indexation & Beta & 0.50 & 0.15 & 0.32 & 0.12 & 0.53 & 0.53 & 0.22 & 0.84 \\
\hline$\iota_{w}:$ wage indexation & Beta & 0.50 & 0.15 & 0.36 & 0.16 & 0.56 & 0.25 & 0.10 & 0.39 \\
\hline$\omega_{H}$ : hour utilization. adjust. cost & Beta & 0.50 & 0.15 & 0.24 & 0.10 & 0.37 & 0.39 & 0.21 & 0.59 \\
\hline$\rho_{n^{s}, u^{:} \text {cross corr }} n^{s}, u$ & Normal & 0.50 & 2.00 & 2.24 & 1.36 & 3.09 & 0.27 & 0.11 & 0.43 \\
\hline$\sigma_{l: \text { inverse Frisch labor supply elasticity }}$ & Normal & 2.00 & 0.75 & 0.56 & 0.14 & 0.97 & 2.29 & 1.25 & 3.29 \\
\hline
\end{tabular}

Monetary policy rule

\begin{tabular}{lccccccccc}
$\rho:$ inertia & Beta & 0.75 & 0.10 & 0.90 & 0.87 & 0.93 & 0.91 & 0.87 & 0.95 \\
$r_{\pi}$ : inflation & Normal & 1.50 & 0.25 & 1.43 & 1.26 & 1.60 & 1.50 & 1.42 & 1.58 \\
$r_{y}:$ output gap & Normal & 0.12 & 0.05 & 0.23 & 0.16 & 0.30 & 0.09 & 0.01 & 0.16 \\
$r_{\Delta y: \text { output growth }}$ & Normal & 0.12 & 0.05 & 0.12 & 0.07 & 0.18 & 0.07 & 0.04 & 0.11 \\
\hline
\end{tabular}

\subsection{Estimation results}

Table 1 shows the posterior estimates of some selected parameters in two panels for Germany and Spain. ${ }^{14}$ The upper panel reports the estimates for parameters characterizing the labor market and nominal rigidities whereas the bottom panel provides the estimated coefficients of the monetary policy rules. In regards to the posterior estimates that measure nominal rigidities, we observe that the sticky-price Calvo probability, $\xi_{p}$, is slightly higher in Germany than in Spain (0.84 versus 0.81$)$, but the sticky-wage Calvo probability, $\xi_{w}$, is much higher in Spain than in Germany (0.93 versus 0.61 ). Hence, price rigidities are quite similar and high in both countries, while wage stickiness last substantially longer in Spain (the estimated duration of the average labor contract is 3.5 years in Spain and slightly less than 8 months in Germany). The price indexation parameter, $\iota_{p}$, is estimated at a higher value in Spain (0.53 versus 0.32), but the wage indexation parameter is somewhat higher in Germany (0.36 versus 0.25$)$.

In addition, Table 1 reports that the parameter measuring the marginal adjustment cost of changing hours per worker, $\omega_{H}$, has a mean value of the posterior estimate equal to 0.53 in Spain and to 0.32 in

\footnotetext{
${ }^{14}$ The Appendix shows the tables containing full estimation results.
} 
Germany. This implies a lower elasticity in demand for hours per worker of Spain relative to the German one (see equation 14). Therefore, variations in the real wage, employment or the hours adjustment shock will have a greater response of hours per worker in the German labor market. The curvature parameter of labor disutility, $\sigma_{l}$, is four times higher in Spain that in Germany (2.29 versus 0.56), which brings a much lower labor supply elasticity in Spain in response to changes in the real wage (see equation 4). Finally, there is a significant discrepancy in the estimated value of the cross effect between the labor force and the rate of unemployment, $\rho_{n^{s}, u}$, with a posterior estimate of 2.24 in Germany, substantially larger than the Spanish estimate at 0.27. This result indicates that the German labor force is quite sensitive to changes in the unemployment rate, whereas this interaction is much weaker in Spain, in a way consistent with the lower labor supply elasticity estimated for Spain.

Summarizing, our estimation results point at differences in nominal wage stickiness, in the rigidities to adjust the hours per worker and in the flexibility of the labor force as the three main structural factors explaining the different labor market outcomes in Germany and Spain. In the comparison, Germany had more flexibility to adjust wages, hours per worker (intensive margin) and the labor supply (extensive margin) which absorbed changes in the demand for labor with little impact left for unemployment variability. As discussed below, the shock decomposition will also provide country-specific exogenous sources of variability with a substantial impact on unemployment fluctuations.

In the estimation of the DSGE model for Germany and Spain we have not imposed any constraint capturing the presence of a common monetary policy for these two countries belonging to the Euro area. Remarkably, the point estimates of most policy parameters are rather similar. Moreover, the standard confidence bands largely overlap. The exception in this pattern is the coefficient associated with the output gap, $r_{y}$, which is roughly twice larger in Germany than in Spain. Hence, the Taylor's central-bank prescription, (27), captures better the responses of the ECB to cyclical fluctuations of the output gap in Germany than in Spain. In order to check whether our estimation results are robust to ignoring the presence of a common monetary policy we have re-estimated the model for Spain using the German interest rate as observable instead of the Spanish interest rate. ${ }^{15}$ Estimation results (not reported here for the sake of brevity) are basically the same indicating that both the German and the Spanish interest rates barely react to the Spanish output gap.

\footnotetext{
${ }^{15}$ The series of short-run nominal interest rate in Germany and Spain are basically identical for the subsample period that goes from 1999 to 2012. Before the launching of the Euro (1999) and during the sovereign debt crisis (after 2012) the Spanish interest rate is higher than the German one.
} 


\section{Model-based evaluation}

This section discusses the differences between the labor markets in Spain and Germany using secondmoment statistics, impulse-response functions and the variance decomposition.

\subsection{Business cycle statistics}

Table 2 (Germany) and Table 3 (Spain) show the second-moment statistics on volatilities, cross correlations and autocorrelations of the four labor market variables for both actual data (top panel) and simulated data using the estimated DSGE model (bottom panel). ${ }^{16}$ As mentioned above, the fluctuations of the unemployment rate are roughly three times more volatile in Spain than in Germany (the standard deviation is $5.51 \%$ in Spain and $1.66 \%$ in Germany). Similarly, the growth rates of the two labor margins have more variability in Spain than in Germany. However, the opposite is true for the rate of nominal wage inflation with a German standard deviation of $0.96 \%$, roughly twice larger than the value reported for Spain $(0.50 \%)$.

Regarding the contemporaneous correlations, we do not observe any substantial comovement between the rate of unemployment and the rates of growth of the two labor margins, with the exception of a moderate negative correlation (-0.36) between the unemployment rate and the employment growth rate in Spain. In addition, the contemporaneous correlation between the unemployment rate and the rate of nominal wage inflation is -0.55 in Spain, in contrast to a much weaker correlation $(-0.10)$ between these two variables in Germany.

As for the first-order autocorrelation statistics, we observe that the unemployment rates are extremely persistent in the two countries, with the same coefficient of autocorrelation at 0.99 . However, there are differences in the fluctuations of the extensive and intensive margins of labor: the quarterly rate of growth of employment is much more persistent in Spain than in Germany, with reported coefficients of autocorrelation 0.84 and 0.21 , respectively; and the rate of growth of the intensive margin is not persistent at all, with negative coefficients of autocorrelation in both economies (probably, due to the strong trend effects that were displayed in Figure 3). Finally, the autocorrelation coefficient of the nominal wage inflation rate is 0.45 in Spain, whereas it turns negative in Germany (-0.19).

In the comparison with the statistics obtained in model simulations, Tables 2 and 3 indicate that our extended DSGE model does a good job in replicating most of the second-moment statistics, which makes it an appropriate tool for examining the business cycle features distinguishing the labor markets

\footnotetext{
${ }^{16}$ The logs of both employment and hours per worker seem to follow a downward trend over the sample period for the two countries. So, we have computed the statistics for the (stationary) growth rates of these two variables (i.e., $\Delta n$ and $\Delta h$ ).
} 
in the two countries. Thus, the model captures the higher volatility of the unemployment rate as well as the lower volatility of wage inflation in Spain compared to Germany. Moreover, the estimated model is able to replicate the null correlations between the unemployment rate and the growth rate of hours per worker in the two countries as well as the low and negative correlations between the unemployment rate and both the employment growth rate and the wage inflation rate in Germany. As for serial inertia, the estimated model mimics the high persistence of the unemployment rate in the two countries as well as the positive (negative) autocorrelation of the rate of nominal wage inflation in Spain (Germany). There are some difficulties in replicating the volatility and persistence of the extensive margin of labor because the model reports standard deviations of $\Delta n$ substantially higher than the ones observed in the data (especially in Germany) and lower coefficients of autocorrelation (especially in Spain). Since the estimation is made using the unemployment rate as observable (and not employment data) the fit of the model to the data is stronger for the series of unemployment than for the series of employment. ${ }^{17}$ Finally, the model also underestimates the negative coefficient of correlation between the unemployment rate and the wage inflation rate in Spain.

Table 2. German second-moment statistics (1996:2-2013:4)

\begin{tabular}{lcccc}
\hline \hline & $u$ & $\triangle n$ & $\triangle h$ & $\pi^{w}$ \\
Actual Data & & & & \\
Std. dev., \% & 1.66 & 0.34 & 0.79 & 0.96 \\
Correlation with $u$ & 1.0 & -0.03 & 0.03 & -0.10 \\
Autocorrelation & 0.99 & 0.21 & -0.25 & -0.19 \\
& & & & \\
Estimated model & & & & \\
Std. dev., \% & 1.40 & 1.09 & 0.71 & 1.30 \\
Correlation with $u$ & 1.0 & -0.12 & 0.00 & -0.06 \\
Autocorrelation & 0.96 & 0.10 & -0.08 & -0.06 \\
\hline
\end{tabular}

\footnotetext{
${ }^{17}$ Another possible explanation for these difficulties is that the growth rates of the two margins of labor mainly capture high-frequency (short-term) labor market fluctuations whereas the model is designed to explain fluctuations at business-cycle frequencies.
} 
Table 3. Spanish second-moment statistics (1996:2-2013:4)

\begin{tabular}{lcccc}
\hline \hline & $u$ & $\triangle n$ & $\triangle h$ & $\pi^{w}$ \\
Actual data & & & & \\
Std. dev., \% & 5.51 & 0.83 & 0.92 & 0.50 \\
Correlation with $u$ & 1.0 & -0.36 & 0.08 & -0.55 \\
Autocorrelation & 0.99 & 0.84 & -0.61 & 0.45 \\
& & & & \\
Estimated model & & & & \\
Std. dev., \% & 4.23 & 1.29 & 0.88 & 0.62 \\
Correlation with $u$ & 1.0 & -0.13 & 0.04 & -0.11 \\
Autocorrelation & 0.97 & 0.16 & 0.02 & 0.57 \\
\hline
\end{tabular}

\subsection{Impulse-response functions}

Figures 6-9 show the responses of output, the rate of unemployment, hours per worker, employment, the labor force, the rate of nominal wage inflation, the rate of price inflation and the nominal interest rate in Germany (solid line) and in Spain (dashed line) to a technology shock, an interest rate shock, an hours adjustment cost shock and a labor force shock, respectively. ${ }^{18}$ The size of the shocks have been normalized to the mean value of the posterior estimated standard deviation across countries.

Figure 6 shows that the responses to a technology shock are larger and more persistent in Spain than in Germany for the unemployment rate, employment, price inflation and the nominal interest rate whereas the opposite occurs for output, wage inflation and the labor force. The rise of productivity reduces the demand for labor in both margins, and the rate of unemployment increases at the time of the shock and gradually falls down to values below the steady-state rate (faster in Germany than in Spain).

Figure 7 displays the responses to an interest rate shock, which are more pronounced and in general more persistent in Spain than in Germany. The exceptions are the reactions of wage inflation and the labor force, which respectively indicate further wage adjustment flexibility and procyclical labor force in Germany. In turn, the unemployment rate is barely affected by monetary policy shocks in Germany. This result gives support to the idea that the ECB's monetary policy has been primarily designed to stabilize the German business cycles. The intensive margin of labor (hours per worker) moves down as demand falls, being the cut lower in Germany due to the severe decline of the real wage.

As expected, Figure 8 documents that a shock to the hours adjustment cost function have effects in opposite direction for the extensive and intensive margins of labor. Thus, a positive realization of this

\footnotetext{
${ }^{18}$ The impulse response functions associated with the remaining five shocks of the model are included in the Appendix.
} 

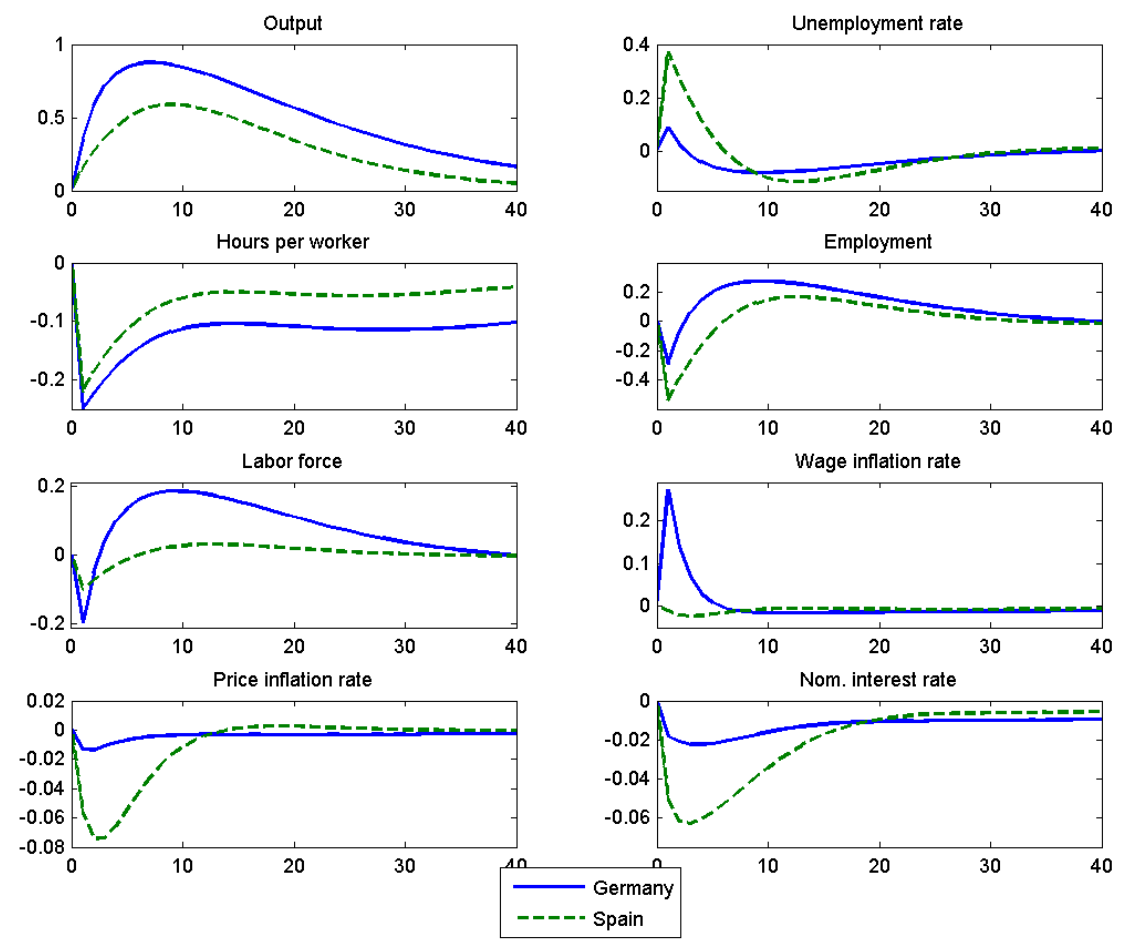

Figure 6: IRFs after a technology shock (one estimated std deviation).

shock makes more attractive to increase employment (labor extensive margin) and reduces hours per worker (labor intensive margin). Somewhat similar to the previous two shocks, the initial responses of all variables -but the labor force- are higher in Spain than in Germany. Nevertheless, the substitution among the two labor margins is more persistent in Germany than in Spain. The job creation that results from this shock moves the rate of unemployment down. In turn, the labor force expands due to the cross effect between labor market participation and unemployment embedded in (6). Such reaction is found much stronger in the impulse-response function of Germany that incorporates a much higher estimate of the cross effect coefficient $\rho_{n^{s}, u}$.

Figure 9 shows quite distinctive responses to a labor force shock in the two countries depending on the variables analyzed. Thus, the nominal variables (price inflation, wage inflation and the nominal interest rate) are barely affected by this shock in the two countries. However, the unemployment rate and the labor force responses are sizeable in the two countries, but more pronounced in Spain. This indicates the relevance of labor force shocks to drive Spanish unemployment fluctuations that will be further examined in Section 5. Finally, even though the responses of output and the two margins of labor are tiny at the time of impact of the labor force shock, the medium-term responses (8-20 quarters ahead of impact) have 

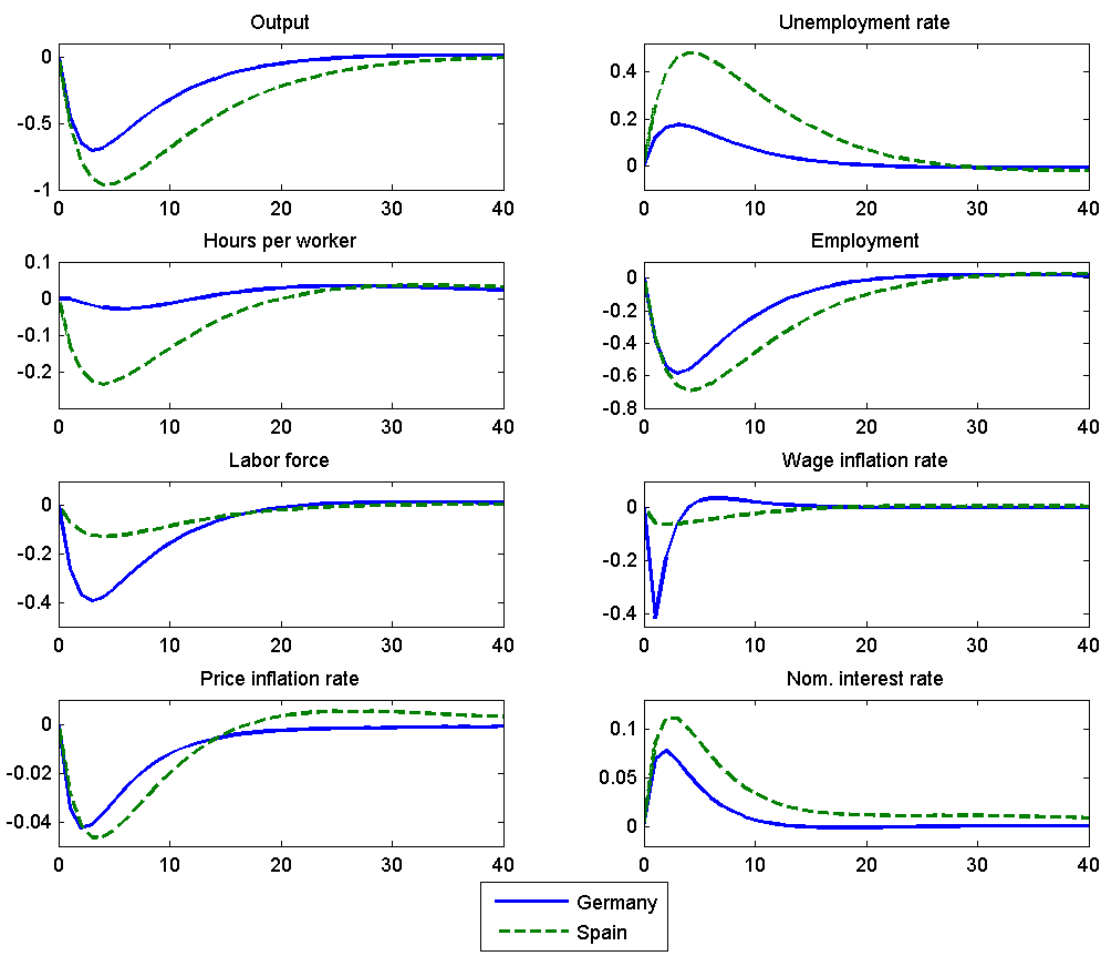

Figure 7: IRFs after an interest-rate shock (one estimated std deviation).

different signs in the two countries showing a sharp difference in the transmission mechanism of this shock across countries.

\subsection{Variance decomposition}

Table 4 brings the long-run variance decomposition (infinite forecast horizon) for fluctuations of output, the unemployment rate, the rates of growth of hours per worker and employment, and the rate of nominal wage inflation in the estimated models for Germany (top panel) and Spain (bottom panel). Output variability is mostly driven by technology shocks in Germany (58\%) and by a combination of demandside shocks on the interest rate and risk premia in Spain (both $\eta^{b}$ and $\eta^{R}$ together account for $68.6 \%$ of output fluctuations). We can also observe in Table 4 that the fluctuations in the unemployment rate in the two countries are mostly explained by either the labor force shock or the hours adjustment cost shock. The former is much more important in Spain (44\% labor force shock and $23 \%$ hours adjustment cost shock), whereas in Germany the two of them have a rather similar share around 35\%. Meanwhile, risk-premium and interest rate shocks together also explain a sizeable share of unemployment fluctuations in Spain (25.7\%) and in Germany (14.5\%). 

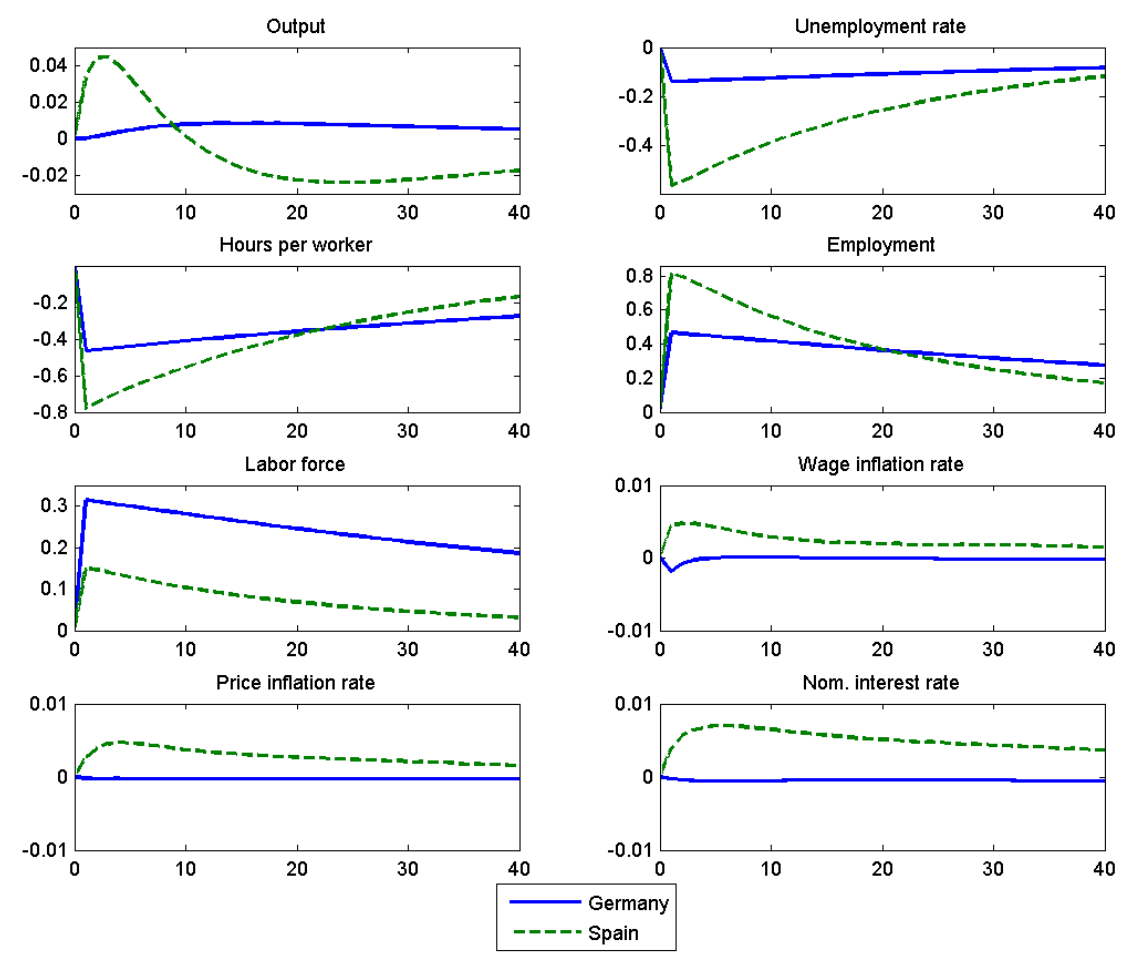

Figure 8: IRFs after an hours adjustment cost shock (one estimated std deviation).
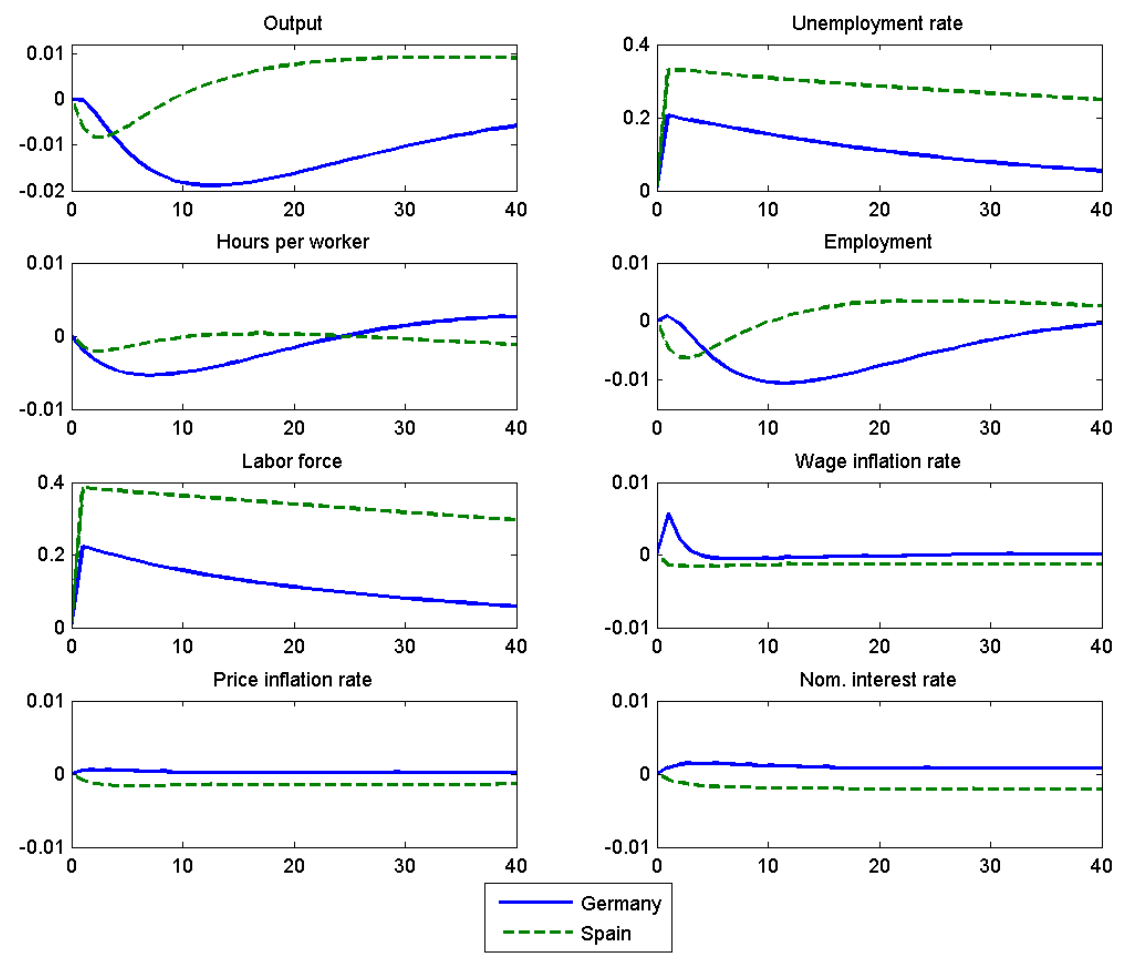

Figure 9: IRFs after a labor force shock (one estimated std deviation). 
The influence of either price-push or wage-push shocks is little for both output and unemployment, especially in Germany (with percentages around $1 \%$ of the overall variability of both variables). In the case of Spain, these shocks account jointly for nearly $8 \%$ of output variability and $3 \%$ of unemployment variability.

Table 4. Variance decomposition, $\%$

\begin{tabular}{|c|c|c|c|c|c|}
\hline \multicolumn{6}{|l|}{ Germany } \\
\hline & $y$ & $u$ & $\triangle h$ & $\triangle n$ & $\pi^{w}$ \\
\hline Technology, $\eta^{a}$ & 58.4 & 4.9 & 12.8 & 14.5 & 5.8 \\
\hline Risk-premium, $\eta^{b}$ & 7.3 & 4.9 & 0.1 & 11.1 & 7.9 \\
\hline Interest-rate, $\eta^{R}$ & 14.5 & 9.6 & 0.1 & 16.6 & 12.8 \\
\hline Investment adj. cost, $\eta^{i}$ & 8.0 & 3.5 & 6.3 & 17.6 & 0.3 \\
\hline Fiscal/Net exports, $\eta^{g}$ & 10.7 & 4.9 & 7.1 & 15.5 & 0.0 \\
\hline Price-push, $\eta^{P}$ & 0.9 & 0.6 & 1.2 & 2.5 & 1.1 \\
\hline Wage-push, $\eta^{W}$ & 0.2 & 0.1 & 29.7 & 3.8 & 72.1 \\
\hline Hours adj. cost, $\eta^{h}$ & 0.0 & 37.9 & 42.8 & 18.4 & 0.0 \\
\hline Labor force, $\eta^{n}$ & 0.0 & 33.6 & 0.0 & 0.0 & 0.0 \\
\hline \multicolumn{6}{|l|}{ Spain } \\
\hline & $y$ & $u$ & $\triangle h$ & $\triangle n$ & $\pi^{w}$ \\
\hline Technology, $\eta^{a}$ & 17.2 & 2.1 & 6.5 & 20.4 & 1.1 \\
\hline Risk-premium, $\eta^{b}$ & 39.8 & 14.7 & 3.8 & 14.7 & 16.3 \\
\hline Interest-rate, $\eta^{R}$ & 28.8 & 11.0 & 3.5 & 13.1 & 5.9 \\
\hline Investment adj. cost, $\eta^{i}$ & 3.6 & 0.9 & 0.7 & 2.4 & 0.3 \\
\hline Fiscal/Net exports, $\eta^{g}$ & 3.1 & 1.5 & 1.5 & 4.9 & 0.7 \\
\hline Price-push, $\eta^{P}$ & 2.2 & 1.7 & 0.4 & 2.9 & 1.9 \\
\hline Wage-push, $\eta^{W}$ & 5.5 & 1.3 & 1.8 & 1.7 & 73.7 \\
\hline Hours adj. cost, $\eta^{h}$ & 0.0 & 22.8 & 81.8 & 39.9 & 0.1 \\
\hline Labor force, $\eta^{n}$ & 0.0 & 44.0 & 0.0 & 0.0 & 0.0 \\
\hline
\end{tabular}

The fluctuations of the growth rate of hours per worker (intensive margin) in Germany are mostly explained by the hours adjustment cost shocks (42.8\%), the wage-push shocks (29.7\%) and the technology shocks (12.8\%), whereas the hours adjustment cost shocks explain $81.8 \%$ of Spanish intensive margin. 
Demand shocks only explain around $10 \%$ of the fluctuations of the growth rate of the intensive margin of labor for the two countries. In regards to the growth rate of employment (extensive margin of labor), the variance decomposition is qualitatively similar to the one associated with the intensive margin of labor with three important differences. First, the hours adjustment cost shock accounts for less employment variability (18.4\% in Germany and 39.9\% in Spain). Second, the influence of technology shocks is much larger in Spain. Finally, the effects of demand-side shocks and interest rate shocks on employment variability are substantial in the two countries. Adding up the shares of $\eta^{b}, \eta^{R}, \eta^{i}$ and $\eta^{g}$ gives percentages of employment growth variability explained by demand-side shocks of $60.8 \%$ in Germany and $35.4 \%$ in Spain. Investment and fiscal-net exports shocks are more important for Germany than for Spain.

Regarding wage inflation fluctuations, there is an important similarity between the two countries: wage-push shocks explain a substantial share of wage inflation fluctuations (more than 70\%). Another important share (around $20 \%$ in the two countries) of these fluctuations are explained by risk premium and interest rate shocks together.

\section{The sources of variability for the rate of unemployment}

Figures 10 (Spain) and 11 (Germany) show the quarter-to-quarter shock decomposition of the rate of unemployment, respectively, together with the plot of the actual deviation of the series from its estimated steady-state value $(15.13 \%)$. Table $5 \mathrm{~A}$ provides the average quarterly contribution of the shocks of the model to the variability of the unemployment rate in Spain, whereas Table 5B does it for Germany.

Looking at Figure 10, we observe two well-marked subperiods. In the quarters that go from 1996 to 2007 there was a downward trend of the rate of unemployment; those were years of economic expansion and a housing bubble in Spain. The short-run variability of the Spanish unemployment rate came from the combination of three main driving shocks. The labor force shock pushed up unemployment by the exogenous increase in the labor supply. As discussed in the Introduction, the immigration flows, the demographic pattern of the baby-boom and the increase in the women's labor force participation rate explain a continuous increase in the labor supply. In the opposite direction, both the interest-rate shock and the hours adjustment cost shock pulled down the Spanish unemployment rate. These latter effects dominate over the former and the rate of unemployment fell to the minimum value observed just before the financial crisis of 2008. The column for the period 96:2-07:3 of Table 5A provides the estimated numerical effects: the monetary shocks and the hours adjustment shock reduced the Spanish rate of unemployment in $-2.9 \%$ and $-2.32 \%$ per quarter, respectively, and the labor force shock had an average impact on it estimated at an increase of $3.15 \%$ per quarter. 


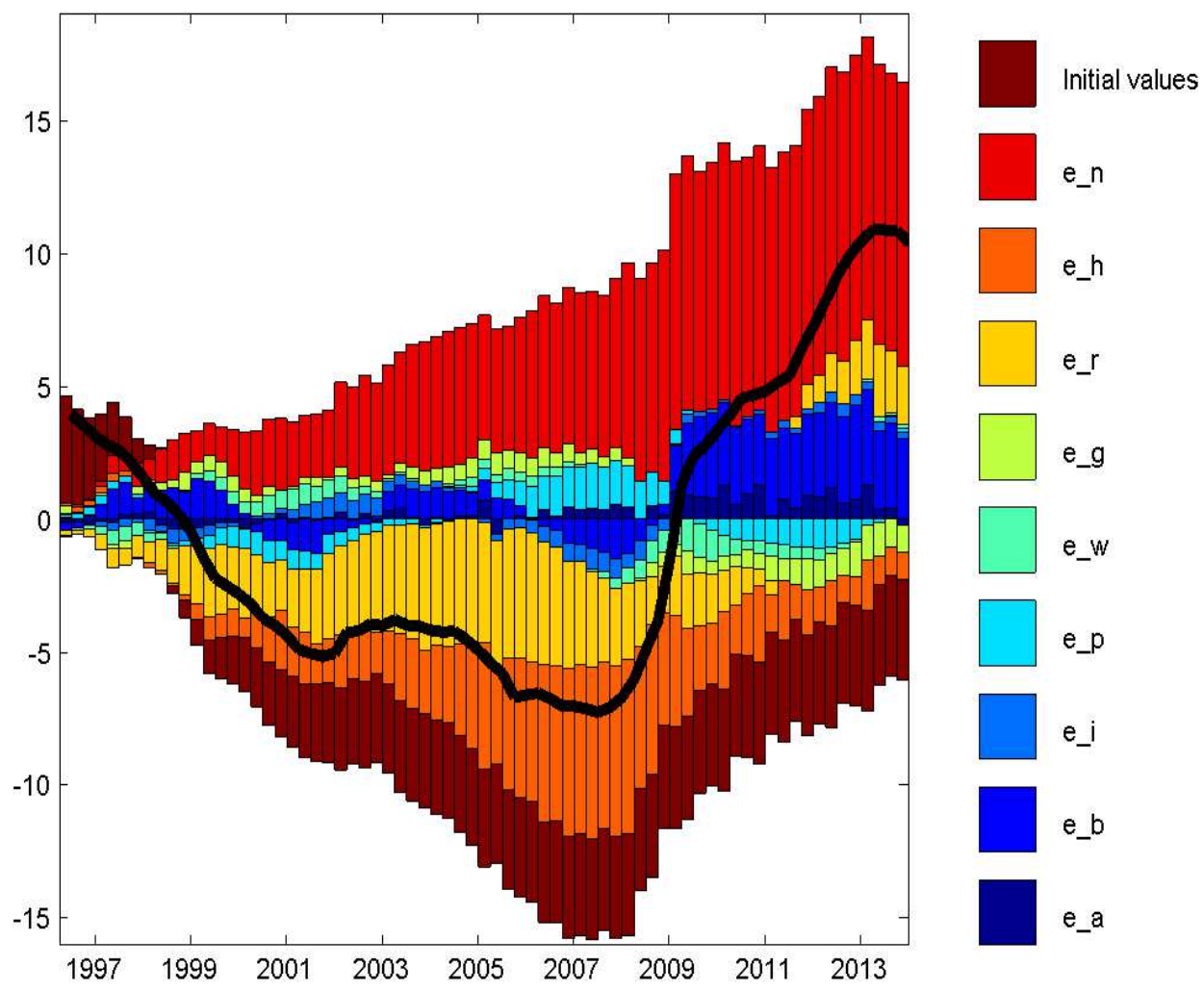

Figure 10: Shock decomposition of the Spanish quarterly rate of unemployment, $\%$.

Our interpretation of the monetary shocks is that the ECB policy boosted the aggregate demand in Spain because the interest rates set for the Euro area were too low for the business cycle phase in Spain. The lack of business cycle synchronization between the business cycles of the core countries (Germany, France) and those of the peripheral countries (e.g. Spain) brought expansionary interest-rate shocks to Spain. Furthermore, nominal wages have been quite rigid in Spain and the desirable increase in nominal wages did not occur to cool down the economic expansion. The other contributor to the reduction in unemployment was the hours adjustment cost shock that kicked in especially after 2002. The progressive flexibility for the hiring processes in Spain may explain this exogenous perturbation, which reduced hours per worker, increased the number of jobs and cut the unemployment rate. The Spanish labour market reform of 2001 changed the regulation to reduce the hiring administrative procedures and facilitated the part-time labor contracts (Gil-Martin, 2002).

The picture changed dramatically during the Great Recession. After 2008, the Spanish unemployment 


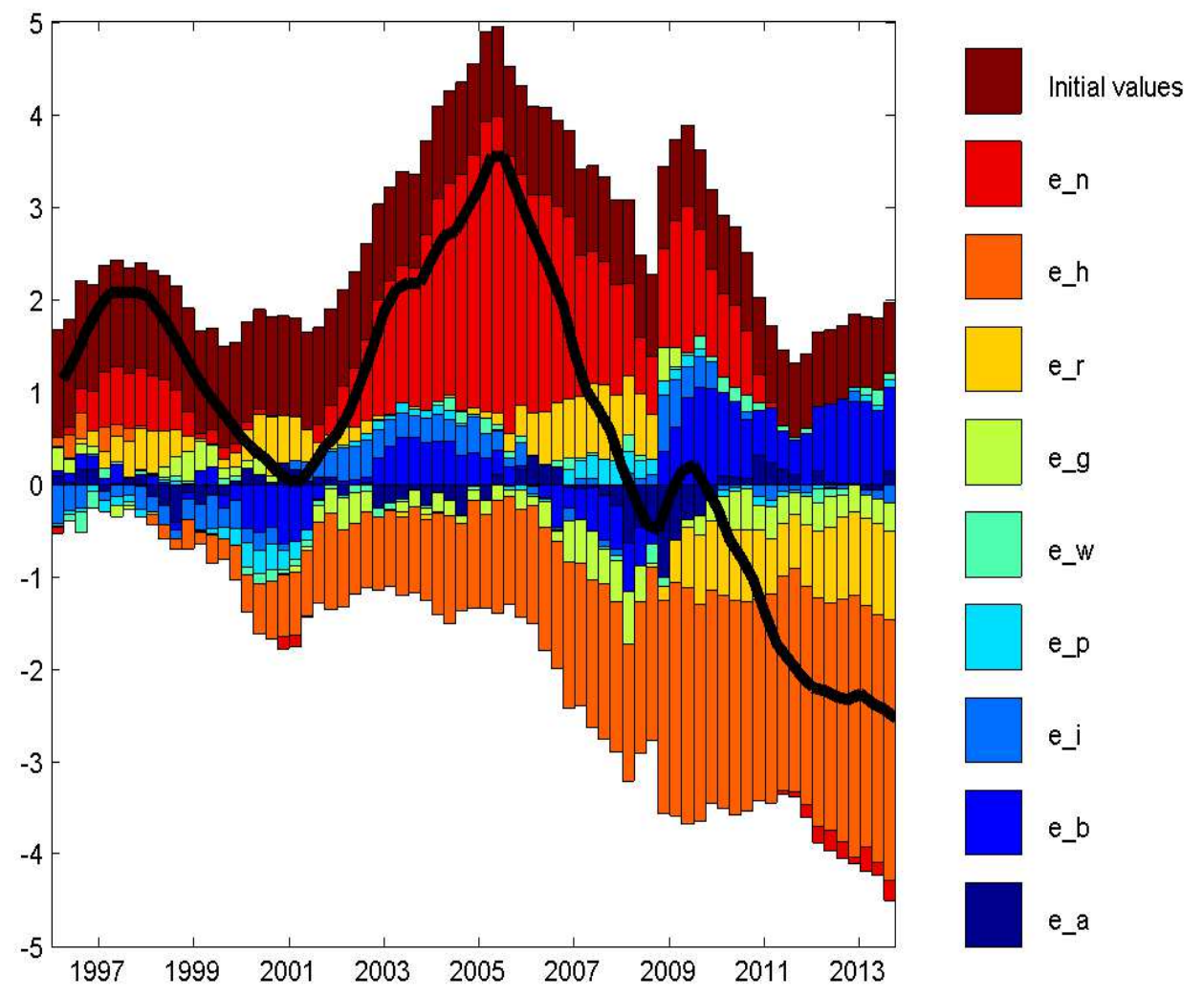

Figure 11: Shock decomposition of the German quarterly rate of unemployment, $\%$. 
rate rose dramatically to reach in 2013 a peak value more than $10 \%$ higher than its estimated steady-state value of $15.13 \%$ (i.e., the unemployment rate reached the $25 \%$ level). In the six-year period from 2008 to 2013, the labor force shocks together with risk-premium shocks -capturing the burst of the housing bubble- gained more importance in the variability of the Spanish unemployment rate. Indeed, these two shocks mostly explain why the Spanish unemployment rose after 2008 (see Figure 10). As informed in the column of the 2007:4-2013:2 sample period of Table 5A, the estimated quarterly contribution of the labor force shocks to the Spanish rate of unemployment was an increase of $9.62 \%$, and the risk-premium shocks pushed it up by $2.22 \%$ per quarter. The role of interest rate shocks was minor, and actually there were contractionary monetary policy shocks which brought job destruction and had pushed the Spanish unemployment rate a bit up over the last quarters of the sample. Finally, the hours adjustment cost shocks gradually decreased their importance since 2008 until the end of the sample, but they still pulled down the rate of unemployment with an average quarterly estimated reduction of $-2.7 \%$.

Figure 11 displays the quarterly decomposition of the unemployment variability in Germany. The deviation of the series from its estimated steady-state value $(7.74 \%)$ is also plotted and we can see that the unemployment rate reached its peak by the middle of 2005 and has ever decreased afterwards with the only exception of a few quarters at the beginning of the Great Recession in 2009. In the central quarters of the sample period, around the maximum value of the German unemployment rate, labor force shocks mainly determined the evolution of the unemployment rate while hours adjustment cost shocks pushed the German unemployment rate down. Both technology shocks and risk-premium shocks also contributed for the reduction of the German rate of unemployment before 2005 (see Table 5B). Since 2009 labor adjustment cost shocks have pushed the German unemployment rate further down, while labor force shocks have progressively lost their importance to become almost negligible. The tension between the rising of the labor force for the demographic reasons mentioned above (immigration flows, baby boom and the increase in female labor participation) and the exogenous fall in hours per worker turned down in favor of the latter which reduced significantly the rate of unemployment from the mid-2000's onwards. As reported in Table 5B, the hours adjustment cost shock explains an average reduction of the German rate of unemployment by $2.05 \%$ in the sample period from $2006-2013$ and this reduction is lower $(1.38 \%)$ over the full sample. These shocks are likely to capture the deep effects of the labor market reforms that Germany implemented between 2003 and 2005, commonly known as the Hartz reforms. As discussed in Engbom et al. (2015), these labor market reforms were followed by a large and persistent decline in unemployment. One of the main elements of the Hartz reforms is the introduction of the so-called "Minijobs" and "Midijobs", which reduced the social security contributions, cutting the labor cost for 
the firm and rasing the net salary for the worker (Jacobi and Jochen, 2006). ${ }^{19}$

In short, the lack of synchronicity of the Spanish and German rates of unemployment during the Great Recession can be explained by the following two factors. First, the labor force shock increased in Spain and decreased in Germany, pushing up the rate of unemployment in Spain and lowering that pressure in Germany due to labor supply fluctuations. We interpret the labor force shock as the exogenous variability of the labor supply coming from a variety of demographic factors, international labor mobility and changes in female labor participation. Second, the hours adjustment shock took a great influence to reduce the rate of unemployment in Germany, whereas in Spain its effect tends to vanish over the Great Recession period. We identify the hours adjustment shock with the exogenous flexibility (regulation) to create more jobs through the splitting up of hours per worker.

For the full sample period, 1996:2-2013:2, the labor force (demographic) shocks explains a 5.43\% increase of the Spanish rate of unemployment, whereas the hours adjustment shocks (labor market reforms) and the (Euro area) monetary policy shocks account for a reduction of it by 2.02 and $2.46 \%$. In the case of Germany, the impact of hours adjustment cost shocks (labor market reforms) brings an estimated fall of the unemployment rate by $1.38 \%$ which is greater than the rise due to (demographic) labor force shocks estimated at $0.9 \%$ per quarter.

Table 5A. Sources of variability of the Spanish quarterly rate of unemployment, $\%$

\begin{tabular}{lccc}
\hline \hline & $96: 2-07: 3$ & $07: 4-13: 2$ & Full sample \\
\cline { 2 - 3 } Technology, $\eta^{a}$ & -0.08 & 0.56 & 0.14 \\
Risk-premium, $\eta^{b}$ & 0.29 & 2.22 & 0.97 \\
Investment adj. cost, $\eta^{i}$ & -0.03 & 0.11 & 0.02 \\
Price-push, $\eta^{P}$ & 0.18 & -0.02 & 0.11 \\
Wage-push, $\eta^{W}$ & 0.15 & -0.30 & -0.01 \\
Fiscal/NX, $\eta^{g}$ & 0.39 & -0.71 & 0.01 \\
Interest-rate, $\eta^{R}$ & -2.90 & -0.40 & -2.02 \\
Hours adj. cost, $\eta^{h}$ & -2.32 & -2.70 & -2.46 \\
Labor force, $\eta^{n}$ & 3.15 & 9.62 & 5.43 \\
\hline
\end{tabular}

\footnotetext{
${ }^{19}$ A Minijob is a job generating an income below 400 euros per month. A person holding a Minijob is exempt from social security contributions, which effectively increases net wages. Jobs with incomes between 400 and 800 euros are called Midijobs. For these jobs, social security subsidies are paid at a decreasing rate, depending on the income.
} 
Table 5B. Sources of variability of the German quarterly rate of unemployment, $\%$

\begin{tabular}{lccc}
\hline \hline & $96: 2-05: 4$ & $06: 1-13: 2$ & Full sample \\
\cline { 2 - 4 } Technology, $\eta^{a}$ & -0.12 & 0.01 & -0.05 \\
Risk-premium, $\eta^{b}$ & -0.07 & 0.27 & 0.12 \\
Investment adj. cost, $\eta^{i}$ & 0.09 & -0.08 & 0.00 \\
Price-push, $\eta^{P}$ & -0.05 & 0.07 & 0.02 \\
Wage-push, $\eta^{W}$ & 0.02 & 0.00 & 0.01 \\
Fiscal/NX, $\eta^{g}$ & -0.02 & -0.46 & -0.26 \\
Interest-rate, $\eta^{R}$ & 0.02 & -0.13 & -0.09 \\
Hours adj. cost, $\eta^{h}$ & -0.49 & -2.05 & -1.38 \\
Labor force, $\eta^{n}$ & 0.89 & 1.01 & 0.90 \\
\hline
\end{tabular}

\section{Conclusions}

In this paper, we have extended the medium-scale dynamic stochastic model described in Casares, Moreno and Vázquez (2014) to consider the two margins of total labor variability: the extensive margin (number of workers) and the intensive margin (number of hours per worker). The resulting model combines traditional assumptions of the dynamic stochastic general equilibrium (DSGE) methodology (Smets and Wouters, 2007) with the introduction of unemployment as the excess supply of labor driven by wage stickiness (Casares, 2010). This model has been estimated using German and Spanish quarterly data for the sample period 1996-2013 to study the main differences between the Spanish and German labor market fluctuations. In particular, we explain why the unemployment volatility is much higher in Spain than in Germany.

The main finding is the estimation of large and persistent shocks that raise the Spanish labor force to make it play a prominent role in explaining the volatility of the rate of unemployment in Spain. This result corroborates the empirical evidence on the dramatic increase of the labor force participation rate in Spain, which increased from $63 \%$ to $75 \%$ from 1996 to 2013. A combination of demographic factors such as the inflow of immigrants, the entry of the baby-boom generation in the labor market and the rise of female participation are behind this fact. In the estimated model, the unemployment-augmenting labor force shocks explain a $5.43 \%$ increase in the Spanish rate of unemployment. For Germany, the labor force shocks only account for an estimated $0.90 \%$ rise of its rate of unemployment.

Other four factors that have also contributed to explain the large differences between the German and Spanish labor markets are the following: wage rigidity has been much higher in Spain than in Germany, 
the labor force has been much more elastic to changes in either the real wage or the unemployment rate in Germany than in Spain, there have been persistent shocks in the German hours per worker that moved down the unemployment rate (which could be capturing the effects of the Hartz reforms with the massive use of minijob contracts), and the ECB's policy design brought monetary shocks with much greater influence to the Spanish unemployment rate. Interestingly, demand-side shocks on consumption, investment and government spending had only a minor impact on the labor markets of these two countries.

\section{References}

Arango, J. (2013) Exceptional in Europe? Spain's experience with immigration and integration. Washington, DC: Migration Policy Institute.

Boeri, T., and J.F. Jimeno (2016) Learning from the great divergence in unemployment in Europe during the crisis. Labour Economics 41, 32-46.

Boscà, J.E., A. Díaz, R. Doménech, J. Ferri, E. Pérez and L. Puch (2010) A rational expectations model for simulation and policy evaluation of the Spanish economy. SERIEs: Journal of the Spanish Economic Association 1, 135-169.

Calvo, G.A. (1983). Staggered pricing in a utility-maximizing framework. Journal of Monetary Economics 12, 383-396.

Casares, M. (2010) Unemployment as excess supply of labor. Journal of Monetary Economics 57, $233-243$.

Casares, M., A. Moreno, and J. Vázquez (2014) An estimated New-Keynesian model with unemployment as excess supply of labor. Journal of Macroeconomics 40, 338-359.

Christiano, L.J., M. Eichenbaum, and C.L. Evans (2005) Nominal rigidities and the dynamic effects of a shock to monetary policy. Journal of Political Economy 113, 1-45.

Dixit, A.K., and J.E. Stiglitz (1977) Monopolistic competition and optimum product diversity. American Economic Review 67, 297-308.

Dvorkin, M., and H. Shell (2015) A cross-country comparison of labor force participation. Federal Reserve Bank of St. Louis Economic Synopses 17.

Engbom, N., E. Detragiache, and F. Raei (2015) The German labor market reforms and postunemployment earnings. IMF Working Paper 15/162.

Erceg, C. J., D. W. Henderson, and A. T. Levin (2000) Optimal Monetary Policy with Staggered Wage and Price Contracts. Journal of Monetary Economics 46, 281-314.

Galí, J. (2011) The return of the wage Phillips curve. Journal of the European Economic Association 9, 436-461. 
Gil-Martín, S. (2002) An overview of Spanish labour market reforms, 1985-2002. Unidad de Políticas Comparadas (CSIC), Working Paper 02-17.

Jacobi, L., and K. Jochen (2006) Before and after the Hartz reforms: the performance of active labour market policy in Germany. IZA DP No. 2100.

Ohanian, L.E., and A. Raffo (2012) Aggregate hours worked in OECD countries: new measurement and implications for business cycles. Journal of Monetary Economics 59, 40-56.

Phillips, A.W. (1958) The relation between unemployment and the rate of change of money wage rates in the United Kingdom, 1861-1957. Economica 25, 283-299.

Smets, F.R., and R. Wouters (2003) An estimated dynamic stochastic general equilibrium model of the Euro area. Journal of the European Economic Association 1, 1123-1175.

Smets, F.R., and R. Wouters (2007) Shocks and frictions in U.S. business cycles: a Bayesian DSGE approach. American Economic Review 97, 586-606.

Taylor, J.B. (1993). Discretion versus policy rules in practice. Carnegie-Rochester Conference Series on Public Policy 39, 195-214. 


\section{Technical Appendix}

A. New-Keynesian model with unemployment, variable capital and both intensive and extensive margins for labor.

Set of log-linearized dynamic equations:

Aggregate resource constraint:

$$
y_{t}=c_{y} c_{t}+i_{y} i_{t}+z_{y} z_{t}+\varepsilon_{t}^{g}
$$

where $c_{y}=\frac{C}{Y}=1-g_{y}-i_{y}, i_{y}=\frac{I}{Y}=(\gamma-1+\delta) \frac{K}{Y}$, and $z_{y}=r^{k} \frac{K}{Y}$ are steady-state ratios. As in Smets and Wouters (2007), the depreciation rate and the exogenous spending-GDP ratio are fixed in the estimation procedure at $\delta=0.025$ and $g_{y}=0.18$.

Consumption equation:

$c_{t}=\frac{\lambda / \gamma}{1+\lambda / \gamma} c_{t-1}+\frac{1}{1+\lambda / \gamma} E_{t} c_{t+1}-\frac{1-\lambda / \gamma}{\sigma_{c}(1+\lambda / \gamma)}\left(r_{t}-r+\varepsilon_{t}^{b}\right)+\frac{\left(\sigma_{c}-1\right)\left(1-u^{n}\right)^{1+\sigma_{l}} N H w / c}{\sigma_{c}(1+\lambda / \gamma)}\left(l_{t}^{s}-E_{t} l_{t+1}^{s}-\left(u_{t}-E_{t} u_{t+1}\right)\right)$.

Investment equation:

$$
i_{t}=i_{1} i_{t-1}+\left(1-i_{1}\right) E_{t} i_{t+1}+i_{2} q_{t}+\varepsilon_{t}^{i}
$$

where $i_{1}=\frac{1}{1+\bar{\beta}}$, and $i_{2}=\frac{1}{(1+\bar{\beta}) \gamma^{2} \varphi}$ with $\bar{\beta}=\beta \gamma^{\left(1-\sigma_{c}\right)}$.

Arbitrage condition (value of capital, $q_{t}$ ):

$$
q_{t}=q_{1} E_{t} q_{t+1}+\left(1-q_{1}\right) E_{t} r_{t+1}^{k}-\left(R_{t}-E_{t} \pi_{t+1}-\left(\frac{1-h / \gamma}{\sigma_{c}(1+h / \gamma)}\right)^{-1} \varepsilon_{t}^{b}\right)
$$

where $q_{1}=\bar{\beta} \gamma^{-1}(1-\delta)=\frac{(1-\delta)}{\left(r^{k}+1-\delta\right)}$.

Log-linearized aggregate production function:

$$
y_{t}=\Phi_{y}\left(\alpha k_{t}^{s}+(1-\alpha)\left(h_{t}^{d}+n_{t}^{d}\right)+\varepsilon_{t}^{a}\right)
$$

where $\Phi_{y}=1+\frac{\phi}{Y}=1+\frac{\text { Steady-state fixed cost }}{Y}$ and $\alpha$ is the capital-share in the production function. ${ }^{20}$

Effective capital (with one period time-to-build):

$$
k_{t}^{s}=k_{t-1}+z_{t} .
$$

Capital utilization:

$$
z_{t}=z_{1} \log r_{t}^{k}
$$

where $z_{1}=\frac{1-\psi}{\psi}$.

\footnotetext{
${ }^{20}$ From the zero profit condition in steady-state, it should be noticed that $\Phi_{y}$ also represents the value of the steady-state price mark-up.
} 
Capital accumulation equation:

$$
k_{t}=k_{1} k_{t-1}+\left(1-k_{1}\right) i_{t}+k_{2} \varepsilon_{t}^{i}
$$

where $k_{1}=\frac{1-\delta}{\gamma}$ and $k_{2}=\left(1-\frac{1-\delta}{\gamma}\right)(1+\bar{\beta}) \gamma^{2} \varphi$.

Price markup (negative of the log of the real marginal cost):

$$
\mu_{t}=\alpha\left(k_{t}^{s}-\left(h_{t}^{d}+n_{t}^{d}\right)\right)+\varepsilon_{t}^{a}-\left(w_{t}-p_{t}\right) .
$$

New-Keynesian Phillips curve (price inflation dynamics):

$$
\pi_{t}-\pi=\frac{\iota_{p}}{1+\bar{\beta} \iota_{p}}\left(\pi_{t-1}-\pi\right)+\frac{\bar{\beta}}{1+\bar{\beta} \iota_{p}} E_{t}\left(\pi_{t+1}-\pi\right)-\frac{\left(1-\bar{\beta} \xi_{p}\right)\left(1-\xi_{p}\right)}{\left(1+\bar{\beta} \iota_{p}\right) \xi_{p} \Phi} \mu_{t}^{p}+\varepsilon_{t}^{p}
$$

where $\Phi=\left(\left(\Phi_{y}-1\right) \varepsilon_{p}+1\right)\left(1+\tau_{2}\left(1-\frac{\left(1-\bar{\beta} \xi_{p}\right) \xi_{w}}{1-\bar{\beta} \xi_{p} \xi_{w}}\right)\right)$. The coefficient of the curvature of the Kimball goods market aggregator is fixed in the estimation procedure at $\varepsilon_{p}=10$ as in Smets and Wouters (2007).

Optimal demand for capital by firms:

$$
-\left(k_{t}^{s}-\left(h_{t}^{d}+n_{t}^{d}\right)\right)+\left(w_{t}-p_{t}\right)=\log r_{t}^{k}
$$

Rate of unemployment:

$$
u_{t}-u^{n}=\left(1-u^{n}\right)\left(n_{t}^{s}-n_{t}^{d}\right)
$$

Wage inflation equation:

$$
\pi_{t}^{w}-\pi^{w}=\bar{\beta} E_{t}\left(\pi_{t+1}^{w}-\pi^{w}\right)+\iota_{w}\left(\pi_{t-1}-\pi\right)-\bar{\beta} \iota_{w}\left(\pi_{t}-\pi\right)-\phi_{w}\left(l_{t}^{s}-l_{t}^{d}\right)+\left(1-\iota_{w}\right)\left(\varepsilon_{t}^{w}-\bar{\beta} E_{t} \varepsilon_{t+1}^{w}\right),
$$

where the slope coefficient is $\phi_{w}=\frac{\left(1-\bar{\beta} \xi_{w}\right)\left(1-\xi_{w}\right)}{\xi_{w}\left(\sigma_{l}^{-1}+\alpha\right)(1+\Lambda)}$ and $\Lambda=\frac{\tau_{1} \bar{\beta} \xi_{w}\left(\Phi_{y}-1\right)}{\sigma_{l}^{-1}+\alpha}\left(1-\frac{\xi_{p}\left(1-\bar{\beta} \xi_{w}\right)}{1-\bar{\beta} \xi_{w} \xi_{p}}\right) \cdot{ }^{21}$

Real wage dynamics:

$$
\left(w_{t}-p_{t}\right)=\left(w_{t-1}-p_{t-1}\right)+\left(\pi_{t}^{w}-\pi^{w}\right)-\left(\pi_{t}-\pi\right)
$$

Supply of total labor hours:

$$
l_{t}^{s}=\frac{1}{\sigma_{l}}\left(\left(w_{t}-p_{t}\right)-\frac{1}{(1-\lambda / \gamma)}\left(c_{t}-(\lambda / \gamma) c_{t-1}\right)\right) .
$$

Labor force (extensive margin of labor supply):

$$
n_{t}^{s}=\varepsilon_{t}^{N^{s}}-\rho_{n u}\left(u_{t}-u\right)
$$

Demand for hours per worker:

$$
\left(2+\frac{\omega_{H}}{1-\omega_{H}}\right) h_{t}^{d}=n_{t}^{d}-\left(w_{t}-p_{t}\right)-\varepsilon_{t}^{h} .
$$

\footnotetext{
${ }^{21}$ See Casares et al. (2014) for a detailed derivation of the analytical solution of the slope coefficient.
} 
Labor supply decomposition

$$
l_{t}^{s}=h_{t}^{s}+n_{t}^{s}
$$

Labor demand decomposition

$$
l_{t}^{d}=h_{t}^{d}+n_{t}^{d}
$$

Monetary policy rule:

$$
\left(R_{t}-R\right)=\rho\left(R_{t-1}-R\right)+(1-\rho)\left[r_{\pi}\left(\pi_{t}-\pi\right)+r_{y} \widetilde{y}_{t}\right]+r_{\Delta y}\left[\widetilde{y}_{t}-\widetilde{y}_{t-1}\right]+\varepsilon_{t}^{R} .
$$

Output gap definition:

$$
\widetilde{y}_{t}=y_{t}-y_{t}^{p} \text {. }
$$

Potential (natural-rate) variables are obtained assuming flexible prices, flexible wages and shutting down price markup and wage indexation shocks. They are denoted by adding a superscript " $p$ ". The endogenous variables of fluctuations on the markup and the rate of unemployment are dropped because they are equal to zero all the periods $\left(\mu_{t}=0\right.$ and $\left(u_{t}-u^{n}\right)=0$

Flexible-price condition (no price markup fluctuations, and $\mu_{t}=0$ ) replaces the price inflation equation:

$$
\alpha\left(k_{t}^{s, p}-\left(h_{t}^{d, p}+n_{t}^{d, p}\right)\right)+\varepsilon_{t}^{a}=\left(w_{t}^{p}-p_{t}^{p}\right)
$$

Flexible-wage condition (no wage indexation shock fluctuations, and $h_{t}^{s, p}+n_{t}^{s, p}=h_{t}^{d, p}+n_{t}^{d, p}$ ) replaces the wage inflation equation:

$$
\frac{1}{\sigma_{l}}\left(\left(w_{t}-p_{t}\right)-\frac{1}{(1-\lambda / \gamma)}\left(c_{t}-(\lambda / \gamma) c_{t-1}\right)\right)=\left(2+\frac{\omega_{H}}{1-\omega_{H}}\right)^{-1}\left(n_{t}^{d}-\left(w_{t}-p_{t}\right)-\varepsilon_{t}^{h}\right)+n_{t}^{d, p} .
$$

\section{Equations-and-variables summary}

- Set of equations:

Eqs. (A1)-(A21) and the corresponding 18 additional equations of the potential (natural-rate) block of the model (the output gap definition has no correspondence and definitions of $\mu_{t}=0$ and $\left(u_{t}-u^{n}\right)$ are taken away) bring a total 39 semi-loglinearized dynamic equations.

- List of endogenous and exogenous variables:

Endogenous variables (39): $y_{t}, c_{t}, i_{t}, z_{t}, l_{t}^{d}, h_{t}^{d}, n_{t}^{d}, l_{t}^{s}, h_{t}^{s}, n_{t}^{s},\left(R_{t}-R\right),\left(\pi_{t}-\pi\right),\left(\pi_{t}^{w}-\pi^{w}\right), q_{t}$, $\log r_{t}^{k}, k_{t}^{s}, k_{t},\left(u_{t}-u^{n}\right), \mu_{t},\left(w_{t}-p_{t}\right), \widetilde{y}_{t}, y_{t}^{p}, c_{t}^{p}, i_{t}^{p}, z_{t}^{p}, l_{t}^{d, p}, h_{t}^{d, p}, n_{t}^{d, p}, l_{t}^{s, p}, h_{t}^{s, p}, n_{t}^{s, p},\left(R_{t}^{p}-R\right),\left(\pi_{t}^{p}-\pi\right)$, $\left(\pi_{t}^{w, p}-\pi^{w}\right), q_{t}^{p}, \log r_{t}^{k, p}, k_{t}^{s, p}, k_{t}^{p}$, and $\left(w_{t}^{p}-p_{t}^{p}\right)$.

Exogenous variables (9): $\operatorname{AR}(1)$ technology shock $\varepsilon_{t}^{a}=\rho_{a} \varepsilon_{t-1}^{a}+\eta_{t}^{a}, \operatorname{AR}(1)$ risk premium shock $\varepsilon_{t}^{b}=\rho_{b} \varepsilon_{t-1}^{b}+\eta_{t}^{b}, \operatorname{AR}(1)$ exogenous spending shock cross-correlated to technology innovations $\varepsilon_{t}^{g}=$ 
$\rho_{g} \varepsilon_{t-1}^{g}+\eta_{t}^{g}+\rho_{g a} \eta_{t}^{a}, \operatorname{AR}(1)$ investment shock $\varepsilon_{t}^{i}=\rho_{i} \varepsilon_{t-1}^{i}+\eta_{t}^{i}, \operatorname{AR}(1)$ monetary policy shock $\varepsilon_{t}^{R}=$ $\rho_{R} \varepsilon_{t-1}^{R}+\eta_{t}^{R}, \operatorname{ARMA}(1,1)$ price markup shock $\varepsilon_{t}^{p}=\rho_{p} \varepsilon_{t-1}^{p}+\eta_{t}^{p}-\mu_{p} \eta_{t-1}^{p}$, ARMA(1,1) wage push shock $\varepsilon_{t}^{w}=\rho_{w} \varepsilon_{t-1}^{w}+\eta_{t}^{w}-\mu_{w} \eta_{t-1}^{w}, \operatorname{AR}(1)$ hours adjustment cost shock $\varepsilon_{t}^{h}=\rho_{h} \varepsilon_{t-1}^{h}+\eta_{t}^{h}$, and $\operatorname{AR}(1)$ labor force shock $\varepsilon_{t}^{N^{s}}=\rho_{N^{s}} \varepsilon_{t-1}^{N^{s}}+\eta_{t}^{N^{s}}$.

\section{B. Derivation of the wage inflation equation}

Wage setting is governed by the intertemporal labor-clearing condition

$$
E_{t}^{\xi_{w}} \sum_{j=0}^{\infty} \bar{\beta}^{j} \xi_{w}^{j}\left(l_{t+j}^{s}(i)-l_{t+j}^{d}(i)\right)=0
$$

where $l_{t+j}^{s}(i)$ and $l_{t+j}^{d}(i)$ are respectively the log deviations, in any $t+j$ period, from their respective steady-state levels of the labor supply of workers and the labor demand for jobs of type- $i$. The labor supply and labor demand behavior were already respectively introduced through Eqs. (5) and (19), which can be generalized for $t+j$ periods and inserted in (9) to obtain

$$
l_{t+j}^{s}(i)-l_{t+j}^{d}(i)=\frac{1}{\sigma_{l}}\left(w_{t+j}(i)-w_{t+j}\right)+\theta \Phi_{y}^{-1}\left(p_{t+j}(i)-p_{t+j}\right)+\alpha\left(w_{t+j}(i)-w_{t+j}\right)+l_{t+j}^{s}-l_{t+j}^{d},
$$

which can be simplified as follows

$$
l_{t+j}^{s}(i)-l_{t+j}^{d}(i)=\left(\sigma_{l}^{-1}+\alpha\right)\left(w_{t+j}(i)-w_{t+j}\right)+\theta \Phi_{y}^{-1}\left(p_{t+j}(i)-p_{t+j}\right)+\left(l_{t+j}^{s}-l_{t+j}\right) .
$$

Substituting (B2) in (B1) yields

$$
E_{t}^{\xi_{w}} \sum_{j=0}^{\infty} \bar{\beta}^{j} \xi_{w}^{j}\left[\left(\sigma_{l}^{-1}+\alpha\right)\left(w_{t+j}(i)-w_{t+j}\right)+\theta \Phi_{y}^{-1}\left(p_{t+j}(i)-p_{t+j}\right)+\left(l_{t+j}^{s}-l_{t+j}\right)\right]=0 .
$$

Using a log-linear approximation to the wage indexation rule (Eq. 21 in the main text of the paper), and recalling that the $i$ firm can set the labor-clearing wage in period $t$, the conditional expectation of future relative wages that cannot be revised in such way becomes

$$
E_{t}^{\xi_{w}}\left(w_{t+j}(i)-w_{t+j}\right)=\left(w_{t}(i)-w_{t}\right)+E_{t} \sum_{k=1}^{j}\left(\iota_{w}\left(\pi_{t+k-1}-\pi\right)+\left(1-\iota_{w}\right) \varepsilon_{t+k}^{w}-\left(\pi_{t+k}^{w}-\pi^{w}\right)\right),
$$

where $\pi_{t+j}^{w}=\log W_{t+j}-\log W_{t+j-1}$ is wage inflation in period $t+j$. The relative wage consistent with (B2) and (B3) is

$$
\begin{aligned}
w_{t}(i)-w_{t}=-\frac{\left(1-\bar{\beta} \xi_{w}\right)}{\alpha+\sigma_{l}^{-1}} E_{t}^{\xi_{w}} \sum_{j=0}^{\infty} \bar{\beta}^{j} \xi_{w}^{j}\left(\theta \Phi_{y}^{-1}\left(p_{t+j}(i)-p_{t+j}\right)+\left(l_{t+j}^{s}-l_{t+j}\right)\right) \\
\quad-E_{t} \sum_{j=1}^{\infty} \bar{\beta}^{j} \xi_{w}^{j}\left(\iota_{w}\left(\pi_{t+j-1}-\pi\right)+\left(1-\iota_{w}\right) \varepsilon_{t+k}^{w}-\left(\pi_{t+j}^{w}-\pi^{w}\right)\right),
\end{aligned}
$$

which implies that the relative wage depends negatively on the stream of the economy-wide rate of unemployment and also negatively on the stream of relative prices. As in Casares (2010), let us introduce 
the following guess: relative optimal pricing and relative wage setting are related to each other in a loglinear fashion in accordance with

$$
\begin{aligned}
\left(p_{t}(i)-p_{t}\right) & =\left(p_{t}^{*}-p_{t}\right)+\tau_{1}\left(w_{t-1}(i)-w_{t-1}\right), \\
\left(w_{t}(i)-w_{t}\right) & =\left(w_{t}^{*}-w_{t}\right)-\tau_{2}\left(p_{t}(i)-p_{t}\right),
\end{aligned}
$$

where $p_{t}^{*}$ is the $\log$ of the average optimal price, $w_{t}^{*}$ is the log of the average optimal wage, and $\tau_{1}$ and $\tau_{2}$ are coefficients to be determined by equilibrium conditions. We want to express the expected stream of relative prices, $E_{t}^{\xi_{w}} \sum_{j=0}^{\infty} \bar{\beta}^{j} \xi_{w}^{j}\left(p_{t+j}(i)-p_{t+j}\right)$, as a function of the current relative prices in order to have a log-linear relation of the type (B5b). Replicating the algebra shown in the technical appendix of Casares et al. (2014), the expected sum of discounted relative prices is

$$
\begin{aligned}
& E_{t}^{\xi_{w}} \sum_{j=0}^{\infty} \bar{\beta}^{j} \xi_{w}^{j}\left(p_{t+j}(i)-p_{t+j}\right)=\frac{1}{1-\bar{\beta} \xi_{w} \xi_{p}}\left(p_{t}(i)-p_{t}\right) \\
+ & \tau_{1}\left(\frac{\bar{\beta} \xi_{w}}{1-\bar{\beta} \xi_{w}}-\frac{\bar{\beta} \xi_{w} \xi_{p}}{1-\bar{\beta} \xi_{w} \xi_{p}}\right)\left(\left(w_{t}(i)-w_{t}\right)-E_{t} \sum_{j=1}^{\infty} \bar{\beta}^{j} \xi_{w}^{j}\left(\left(\pi_{t+j}^{w}-\pi\right)-\iota_{w}\left(\pi_{t+j-1}-\pi\right)-\left(1-\iota_{w}\right) E_{t} \varepsilon_{t+j}^{w}\right)\right) .
\end{aligned}
$$

Substituting (B6) in the relative wage Eq. (B4), we obtain:

$$
\begin{aligned}
(1+\Lambda)\left(w_{t}(i)-w_{t}\right)= & -\frac{\theta \Phi_{y}^{-1}\left(1-\bar{\beta} \xi_{w}\right)}{\left(\alpha+\sigma_{l}^{-1}\right)\left(1-\bar{\beta} \xi_{w} \xi_{p}\right)}\left(p_{t}(i)-p_{t}\right)-\frac{\left(1-\bar{\beta} \xi_{w}\right)}{\left(\alpha+\sigma_{l}^{-1}\right)} E_{t} \sum_{j=0}^{\infty} \bar{\beta}^{j} \xi_{w}^{j}\left(l_{t+j}^{s}-l_{t+j}^{d}\right) \\
& +(1+\Lambda) E_{t} \sum_{j=1}^{\infty} \bar{\beta}^{j} \xi_{w}^{j}\left(\left(\pi_{t+j}^{w}-\pi^{w}\right)-\iota_{w}\left(\pi_{t+j-1}-\pi\right)-\left(1-\iota_{w}\right) \varepsilon_{t+j}^{w}\right),
\end{aligned}
$$

with $\Lambda=\frac{\tau_{1} \bar{\beta} \xi_{w} \theta \Phi_{y}^{-1}}{\alpha+\sigma_{l}^{-1}}\left(1-\frac{\xi_{p}\left(1-\bar{\beta} \xi_{w}\right)}{1-\bar{\beta} \xi_{w} \xi_{p}}\right) \cdot{ }^{22}$ Eq. (B7) proves right the linear conjecture (B5b), with the following analytical solution for $\tau_{2}$

$$
\tau_{2}=\frac{\theta \Phi_{y}^{-1}\left(1-\bar{\beta} \xi_{w}\right)}{\left(\alpha+\sigma_{l}^{-1}\right)\left(1-\bar{\beta} \xi_{w} \xi_{p}\right)(1+\Lambda)}
$$

and the following expression for the average labor-clearing wage set in period $t$

$w_{t}^{*}=w_{t}-\frac{\left(1-\bar{\beta} \xi_{w}\right)}{\left(\sigma_{l}^{-1}+\alpha\right)(1+\Lambda)} E_{t} \sum_{j=0}^{\infty} \bar{\beta}^{j} \xi_{w}^{j}\left(l_{t+j}^{s}-l_{t+j}^{d}\right)+E_{t} \sum_{j=1}^{\infty} \bar{\beta}^{j} \xi_{w}^{j}\left(\left(\pi_{t+j}^{w}-\pi^{w}\right)-\iota_{w}\left(\pi_{t+j-1}-\pi\right)-\left(1-\iota_{w}\right) \varepsilon_{t+j}^{w}\right)$.

\footnotetext{
${ }^{22}$ The value of $\Lambda$ depends on the coefficient $\tau_{1}$, which measures the elasticity of relative prices to lagged relative wages As derived in the technical appendix of Casares et al. (2014), the analytical solution for $\tau_{1}$ is

$$
\tau_{1}=\frac{A(1-\alpha)\left(1-\bar{\beta} \xi_{p}\right) \xi_{w}}{\left(1-\bar{\beta} \xi_{p} \xi_{w}\right)\left(1+\tau_{2} A(1-\alpha)\left(1-\frac{\left(1-\bar{\beta} \xi_{p}\right) \xi_{w}}{1-\bar{\beta} \xi_{p} \xi_{w}}\right)\right)} .
$$
}


Meanwhile, the wage indexation rule (Eq. 23 in the main text) implies a proportional relationship between the relative wages $w_{t}^{*}-w_{t}$ and the rate of wage inflation, $\pi_{t}^{w}$, adjusted by the indexation factors

$$
w_{t}^{*}-w_{t}=\frac{\xi_{w}}{1-\xi_{w}}\left(\left(\pi_{t}^{w}-\pi^{w}\right)-\iota_{w}\left(\pi_{t-1}-\pi\right)-\left(1-\iota_{w}\right) \varepsilon_{t}^{w}\right) .
$$

Combining (B8) and (B9) results in the wage inflation equation

$$
\pi_{t}^{w}-\pi^{w}=\bar{\beta} E_{t}\left(\pi_{t+1}^{w}-\pi^{w}\right)+\iota_{w}\left(\pi_{t-1}-\pi\right)-\bar{\beta} \iota_{w}\left(\pi_{t}-\pi\right)-\phi_{w}\left(l_{t}^{s}-l_{t}^{d}\right)+\left(1-\iota_{w}\right)\left(\varepsilon_{t}^{w}-\bar{\beta} E_{t} \varepsilon_{t+1}^{w}\right),
$$

where the slope coefficient $\phi_{w}=\frac{\left(1-\bar{\beta} \xi_{w}\right)\left(1-\xi_{w}\right)}{\xi_{w}\left(\sigma_{l}^{-1}+\alpha\right)(1+\Lambda)}$ is analytically determined by the deep parameters of the model.

\section{Full tables with estimation results and additional impulse response functions}

\begin{tabular}{|c|c|c|c|c|c|c|c|c|c|}
\hline & \multicolumn{3}{|c|}{ Priors } & \multicolumn{6}{|c|}{ Posteriors } \\
\hline & \multirow[b]{2}{*}{ Distr } & \multirow[b]{2}{*}{ Mean } & \multirow[b]{2}{*}{ Std D. } & \multicolumn{3}{|c|}{ Germany } & \multicolumn{3}{|c|}{ Spain } \\
\hline & & & & Mean & $5 \%$ & $95 \%$ & Mean & $5 \%$ & $95 \%$ \\
\hline$\varphi:$ cost of adjusting capital & Normal & 4.00 & 1.50 & 4.80 & 2.81 & 6.80 & 6.77 & 5.09 & 8.45 \\
\hline$h$ : habit formation & Beta & 0.70 & 0.10 & 0.70 & 0.54 & 0.87 & 0.48 & 0.35 & 0.60 \\
\hline$\sigma_{c}$ : risk aversion & Normal & 1.50 & 0.37 & 0.92 & 0.87 & 0.98 & 1.32 & 0.91 & 1.71 \\
\hline$\sigma_{l: \text { inverse Frisch elasticity }}$ & Normal & 2.00 & 0.75 & 0.56 & 0.14 & 0.97 & 2.29 & 1.25 & 3.29 \\
\hline$\omega_{h: \text { hours adjustment }}$ & Beta & 0.50 & 0.10 & 0.24 & 0.10 & 0.37 & 0.39 & 0.21 & 0.59 \\
\hline$\xi_{p}$ : price Calvo probability & Beta & 0.50 & 0.10 & 0.84 & 0.78 & 0.91 & 0.81 & 0.75 & 0.87 \\
\hline$\xi_{w}:$ wage Calvo probability & Beta & 0.50 & 0.10 & 0.61 & 0.47 & 0.76 & 0.93 & 0.91 & 0.95 \\
\hline$\iota_{w}:$ price indexation & Beta & 0.50 & 0.15 & 0.36 & 0.16 & 0.56 & 0.25 & 0.10 & 0.39 \\
\hline$\iota_{p}:$ wage indexation & Beta & 0.50 & 0.15 & 0.32 & 0.12 & 0.53 & 0.53 & 0.22 & 0.84 \\
\hline$\psi:$ capital utilizat.. adjust. cost & Beta & 0.50 & 0.15 & 0.56 & 0.35 & 0.77 & 0.79 & 0.65 & 0.93 \\
\hline$r_{\pi}:$ inflation (policy rule) & Normal & 1.50 & 0.25 & 1.43 & 1.26 & 1.60 & 1.50 & 1.42 & 1.58 \\
\hline$\rho:$ inertia (policy rule) & Beta & 0.75 & 0.10 & 0.90 & 0.87 & 0.93 & 0.91 & 0.87 & 0.95 \\
\hline$r_{y}:$ output gap (policy rule) & Normal & 0.12 & 0.05 & 0.23 & 0.16 & 0.30 & 0.09 & 0.01 & 0.16 \\
\hline$r_{\Delta y}$ : output growth (policy rule) & Normal & 0.12 & 0.05 & 0.12 & 0.07 & 0.18 & 0.07 & 0.04 & 0.11 \\
\hline$\pi$ : steady-state inflation & Gamma & $0.24 / 0.60$ & 0.10 & 0.24 & 0.13 & 0.33 & 0.62 & 0.47 & 0.77 \\
\hline $100\left(\beta^{-1}-1\right):$ discount rate & Gamma & 0.25 & 0.10 & 0.19 & 0.08 & 0.29 & 0.22 & 0.08 & 0.34 \\
\hline$\alpha:$ capital share & Normal & 0.30 & 0.05 & 0.27 & 0.23 & 0.32 & 0.20 & 0.15 & 0.24 \\
\hline$U$ : steady-state unemployment rate & Normal & $8.0 / 15.0$ & 2.00 & 7.74 & 6.11 & 9.40 & 15.13 & 12.40 & 18.01 \\
\hline
\end{tabular}

Table A.1.1. Priors and estimated posteriors of the structural parameters (Sample: 1996:2-2013:4) 
Table A.1.2. Priors and estimated posteriors of the shock processes (Sample: 1996:2-2013:4)

\begin{tabular}{|c|c|c|c|c|c|c|c|c|c|}
\hline & \multicolumn{3}{|c|}{ Priors } & \multicolumn{6}{|c|}{ Posteriors } \\
\hline & \multirow[b]{2}{*}{ Distr } & \multirow[b]{2}{*}{ Mean } & \multirow[b]{2}{*}{ Std D. } & \multicolumn{3}{|c|}{ Germany } & \multicolumn{3}{|c|}{ Spain } \\
\hline & & & & Mean & $5 \%$ & $95 \%$ & Mean & $5 \%$ & $95 \%$ \\
\hline$\sigma_{a}:$ Std of productivity innovation & Invgamma & 0.10 & 2.00 & 0.72 & 0.62 & 0.82 & 0.77 & 0.65 & 0.89 \\
\hline$\sigma_{b}:$ Std of risk premium innov. & Invgamma & 0.10 & 2.00 & 0.21 & 0.13 & 0.28 & 0.20 & 0.10 & 0.31 \\
\hline$\sigma_{g}:$ Std of spending innov. & Invgam ma & 0.10 & 2.00 & 3.51 & 3.00 & 3.99 & 2.60 & 2.23 & 2.97 \\
\hline$\sigma_{i}:$ Std of investment innov. & Invgamma & 0.10 & 2.00 & 0.91 & 0.69 & 1.14 & 0.40 & 0.27 & 0.54 \\
\hline$\sigma_{R}:$ Std of monetary innov. & Invgamma & 0.10 & 2.00 & 0.14 & 0.11 & 0.17 & 0.13 & 0.10 & 0.16 \\
\hline$\sigma_{p}:$ Std of price index. innov. & Invgamma & 0.10 & 2.00 & 0.28 & 0.24 & 0.33 & 0.22 & 0.18 & 0.26 \\
\hline$\sigma_{w}:$ Std of wage index. innov. & Invgam ma & 0.10 & 0.10 & 2.74 & 1.24 & 4.49 & 0.68 & 0.44 & 0.94 \\
\hline$\sigma_{h}:$ Std of adjust. labor cost innov. & Invgamma & 0.10 & 0.10 & 1.54 & 1.29 & 1.80 & 2.89 & 2.27 & 3.50 \\
\hline$\sigma_{n}:$ Std of labor force innov. & Invgamma & 0.10 & 0.10 & 0.69 & 0.49 & 0.88 & 0.47 & 0.39 & 0.56 \\
\hline$\rho_{a}:$ Persistence of prod. shock & Beta & 0.50 & 0.20 & 0.95 & 0.91 & 0.99 & 0.92 & 0.88 & 0.96 \\
\hline$\rho_{b}:$ Persistence of risk prem. shock & Beta & 0.50 & 0.20 & 0.88 & 0.82 & 0.95 & 0.95 & 0.91 & 0.99 \\
\hline$\rho_{g}:$ Persistence of spending shock & Beta & 0.50 & 0.20 & 0.95 & 0.91 & 0.99 & 0.98 & 0.96 & 0.998 \\
\hline$\rho_{i}$ : Persistence of investment shock & Beta & 0.50 & 0.20 & 0.32 & 0.13 & 0.51 & 0.56 & 0.34 & 0.77 \\
\hline$\rho_{R}:$ Persistence of monetary shock & Beta & 0.50 & 0.20 & 0.43 & 0.32 & 0.55 & 0.51 & 0.36 & 0.65 \\
\hline$\rho_{p}:$ Persistence of price shock & Beta & 0.50 & 0.20 & 0.51 & 0.17 & 0.81 & 0.54 & 0.19 & 0.87 \\
\hline$\rho_{w}:$ Persistence of wage shock & Beta & 0.50 & 0.20 & 0.47 & 0.17 & 0.79 & 0.72 & 0.55 & 0.92 \\
\hline$\rho_{h}$ : Persistence of adjust. labor cost shock & Beta & 0.50 & 0.20 & 0.99 & 0.98 & 0.998 & 0.96 & 0.94 & 0.99 \\
\hline$\rho_{n}:$ Persistence of labor shock & Beta & 0.50 & 0.20 & 0.97 & 0.94 & 0.99 & 0.99 & 0.99 & 0.999 \\
\hline$\rho_{n^{s}, u}: \operatorname{cross} \operatorname{corr} n^{s}, u$ & Normal & 0.50 & 2.00 & 2.24 & 1.36 & 3.09 & 0.27 & 0.11 & 0.43 \\
\hline$\mu_{p}:$ moving-average of price shock & Beta & 0.50 & 0.20 & 0.83 & 0.74 & 0.92 & 0.50 & 0.24 & 0.76 \\
\hline$\mu_{w}:$ moving-average of wage shock & Beta & 0.50 & 0.20 & 0.53 & 0.27 & 0.80 & 0.33 & 0.11 & 0.54 \\
\hline$\rho_{g a}:$ correlation of prod. $\&$ spend shocks & Beta & 0.50 & 0.20 & 0.63 & 0.36 & 0.93 & 0.50 & 0.18 & 0.81 \\
\hline
\end{tabular}



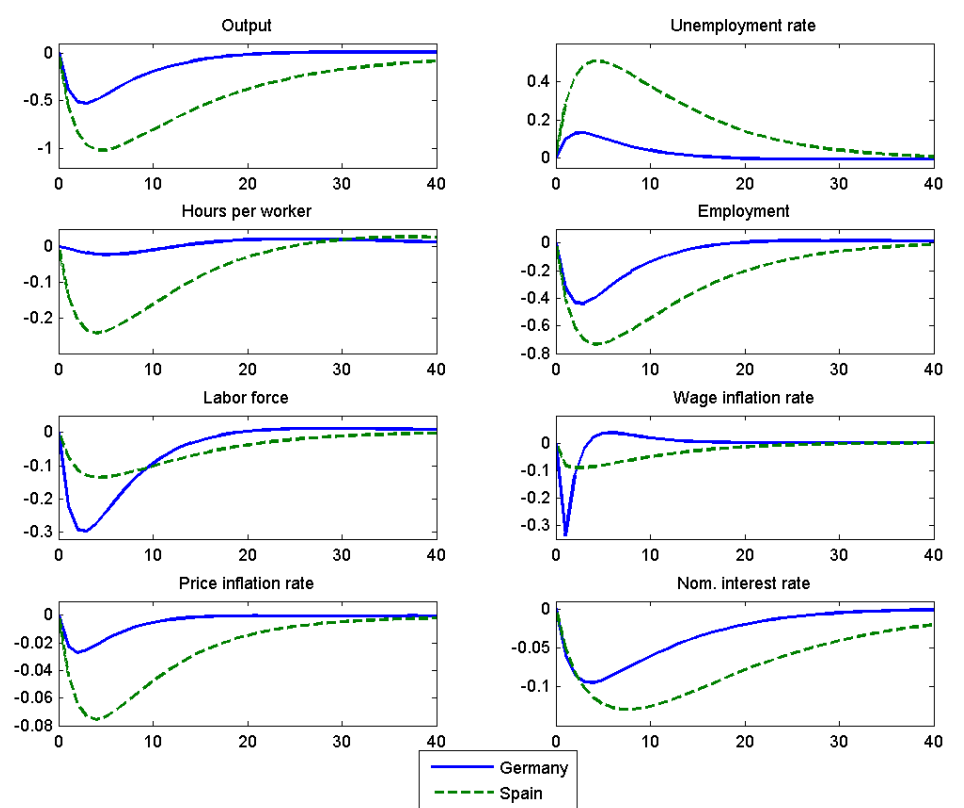

Figure 12: IRFs after a risk-premium shock (one estimated std deviation).
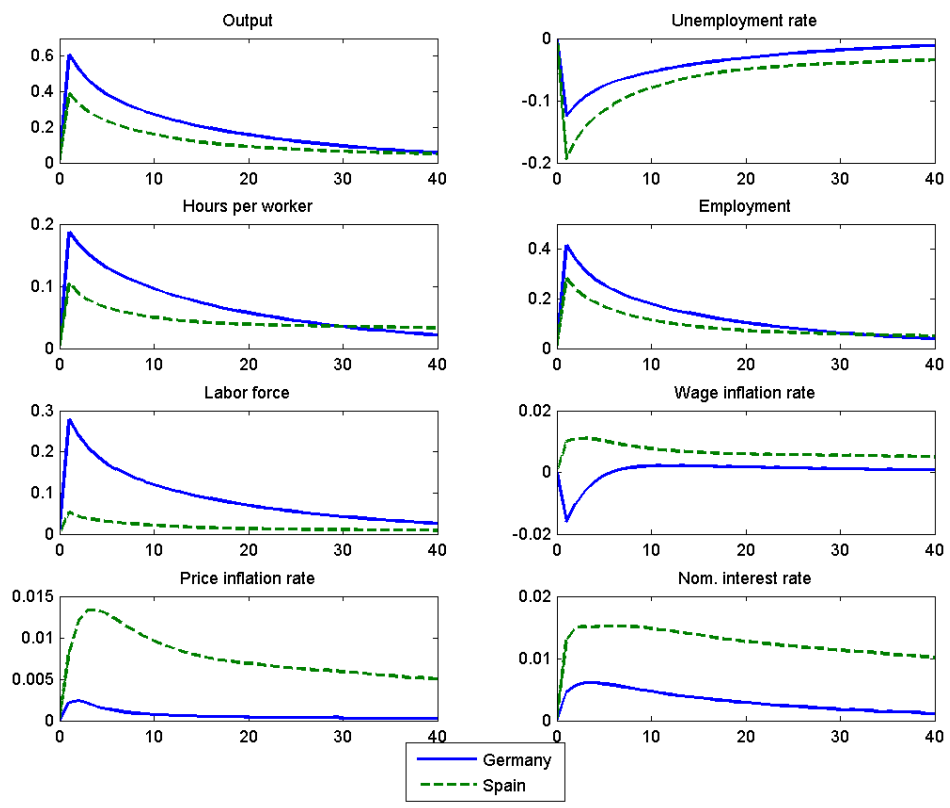

Figure 13: IRFs after a fiscal shock (one estimated std deviation). 

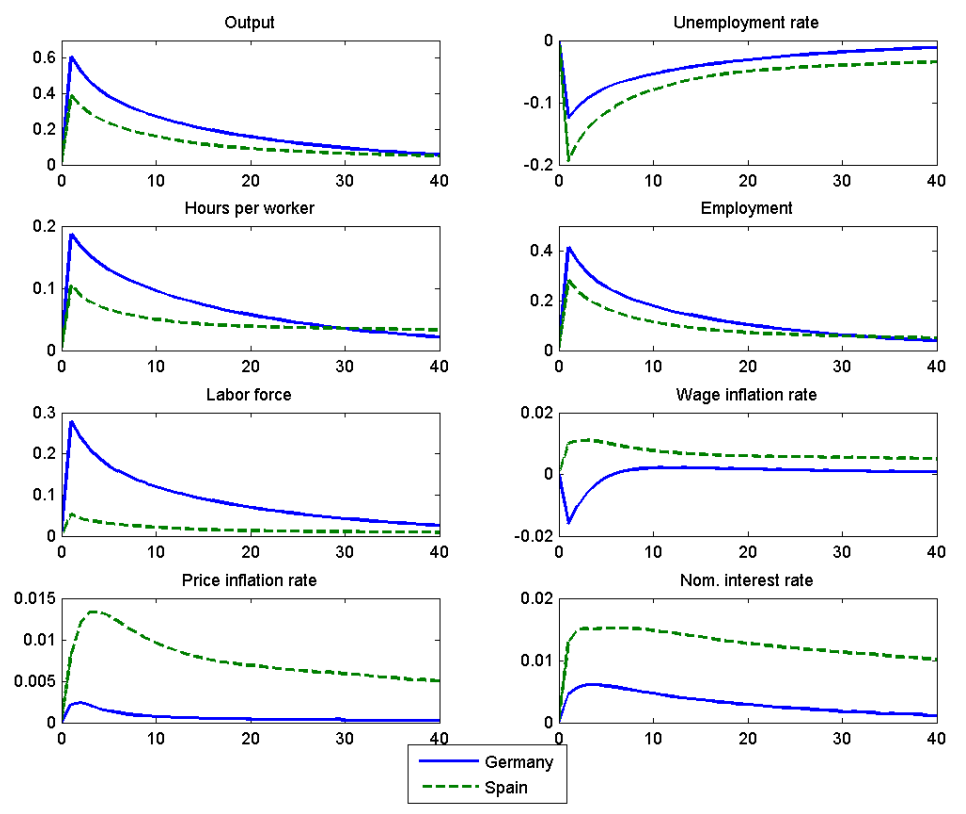

Figure 14: IRFs after a fiscal shock (one estimated std deviation).
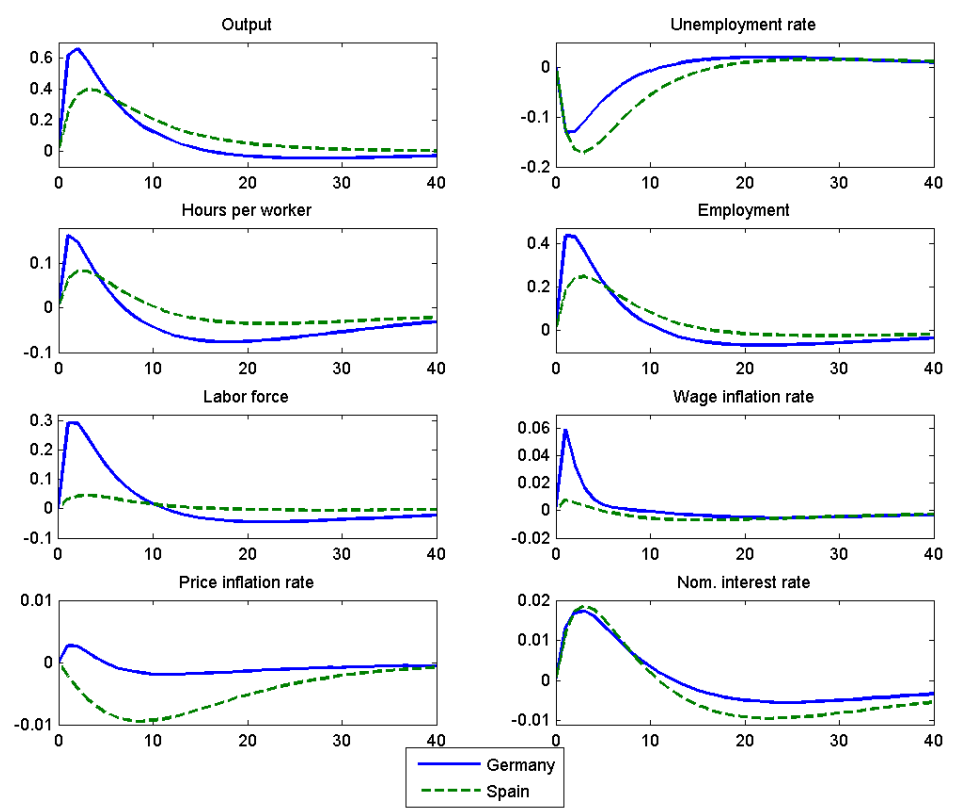

Figure 15: IRFs after an investment shock (one estimated std deviation). 

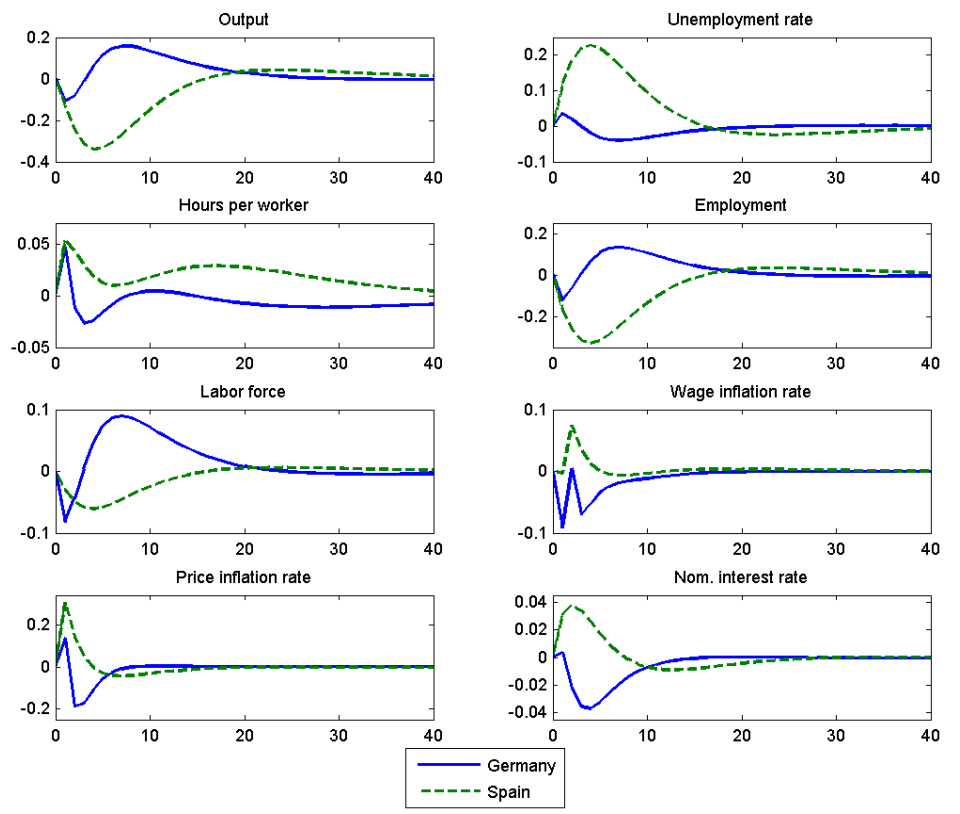

Figure 16: IRFs after a price-push shock (one estimated std deviation).
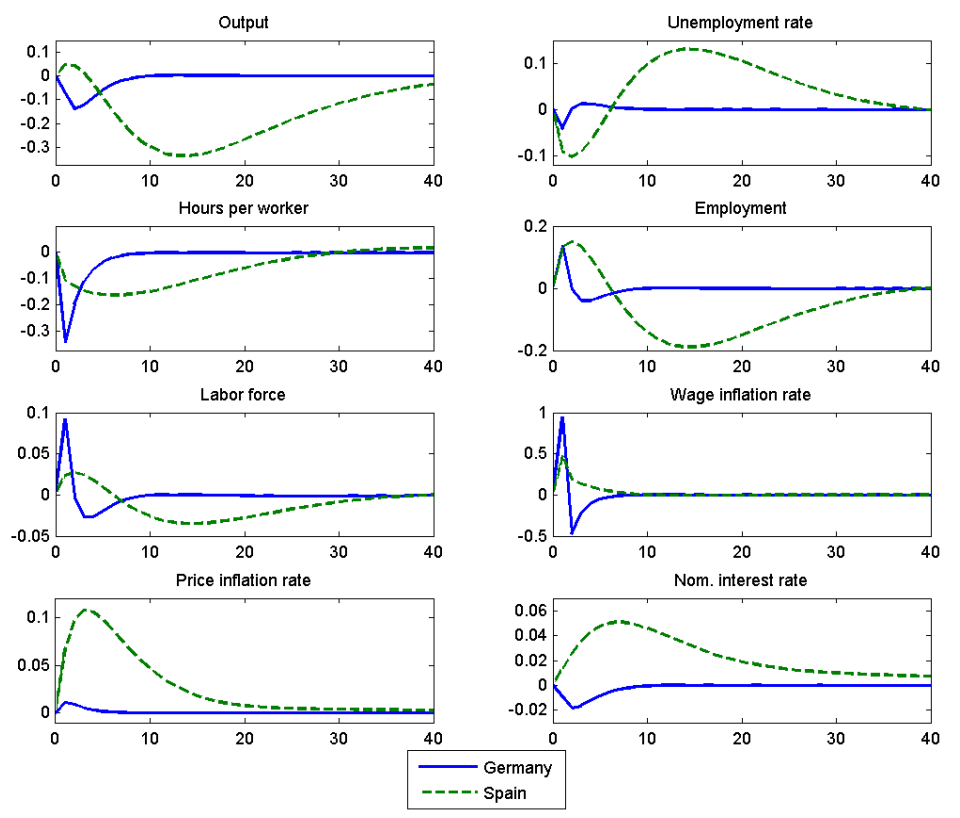

Figure 17: IRFs after a wage-push shock (one estimated std deviation). 